\title{
ADUBAÇÃO VERDE COM LEGUMINOSAS EM ROTAÇÃO COM CANA DE AÇÚCAR (Saccharum spp)
}

\author{
NEIVALDO TUNES CACERES
}

Engenheiro Agrônomo

Orientador: Prof. Dr. José Carlos Alcarde

Dissertação apresentada à Escola Superior de Agricultura "Luiz de Queiroz", da Universidade de São Paulo, para obtenção de título de Mestre em Agronomia, Área de Concentração: Solos e Nutrição de Plantas.

PIRACICABA

Estado de São Paulo - Brasil

Agosto - 1994 
Ficha catalográfica preparada pela Seção de Livros da Divisão de Biblioteca e Documentação - PCLQ/USP

Caceres, Neivaldo Tunes

C118a Adubação verde com leguminosas em rotação com cana-de-açúcar (Saccharum spp). Piracicaba, 1994. $45 p$.

Diss. (Mestre) - ESALQ

Bibliografia.

1. Adubação verde 2. Cana-de-açúcar - Adubação ver de 3. Cana-de-açúcar - leguminosa - Rotação 4. Legumino sa como adubo 5. Rotação de cultura agrícola I. Escola Superior de Agricultura Luiz de Queiroz, Piracicaba

CDD 633.61 


\section{ADUBAÇÃO VERDE COM LEGUMINOSAS EM ROTAÇÃO COM CANA DE AÇÚCAR (Saccharum spp)}

\section{NEIVALDO TUNES CACERES}

Aprovado em: 21.10.1994

Comissão julgadora:

Prof. Dr. José Carlos Alcarde

Prof. Dr. Arnaldo Antonio Rodela

Prof. Dr. Gaspar Henrique Korndorfer
ESALQ/USP ESALQ/USP

Univ. Fed. Uberlândia

Prof. Dr. JOSE CARLOS ALCARDE 
À querida filha Lívia e à amada esposa Denise, pelo absoluto e incondicional apoio, ofereço.

Aos queridos pais José Antonio e Lourdes, e aos sogros Alberto e Hilda, ofereço.

À Deus, por tudo, agradeço. 


\section{Agradecimentos}

- À Brunelli Agricultura S.A. e Usina Costa Pinto S.A., pelo apoio na instalação e condução do experimento de campo.

- À Sementes Pirahy S.A., pela doação das sementes utilizadas no experimento.

- Ao Açúcar Guarani S. A. pelas análises químicas efetuadas e apoio na conclusão do curso e impressão do material.

- Ao CNPq, pela concessão de bolsa de estudo.

- Ao professor e orientador Dr. José Carlos Alcarde, pelo apoio, amizade e confiança. 
SUMÁRIO

Página

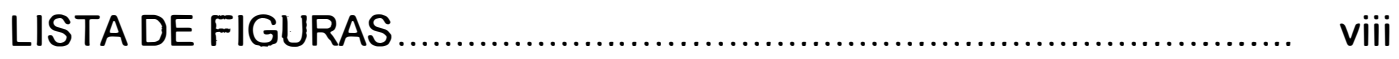

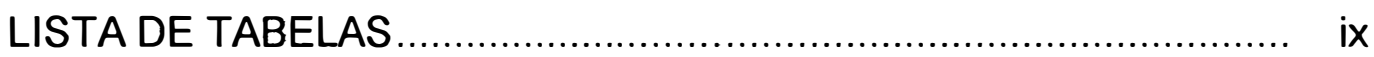

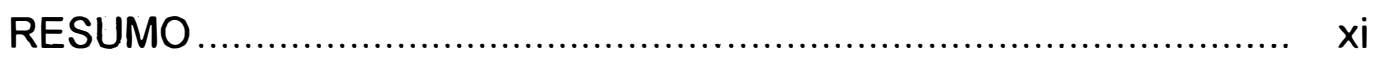

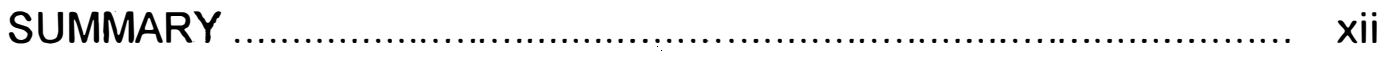

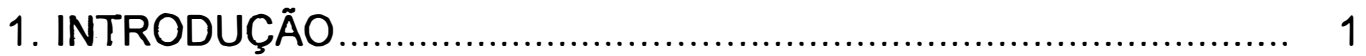

2. REVISÃO DE LITERATURA ................................................ 3

2.1. Aspectos gerais da adubação verde .................................... 3

2.2. Efeitos da adubação verde sobre os atributos do solo ........... 5

2.2.1. Efeito sobre os atributos químicos .............................. 5

2.2.2. Efeito sobre os atributos físicos .................................. 7

2.2.3. Efeito sobre os atributos biológicos .............................. 9

2.3. Resposta de culturas à adubação verde ................................ 11

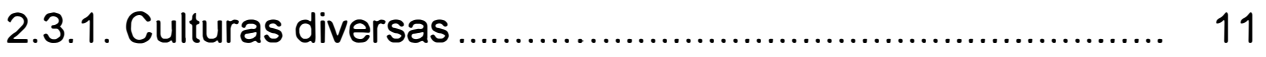

2.3.2. Cana-de-açúcar ........................................................ 14

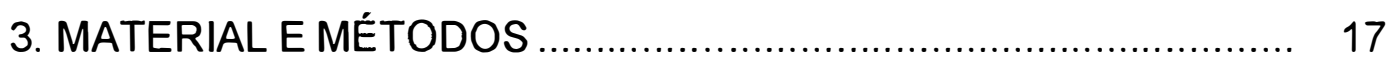

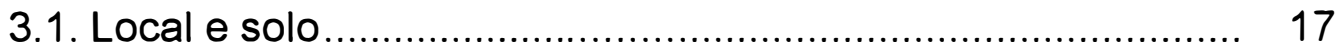

3.2. Delineamento experimental ............................................... 17

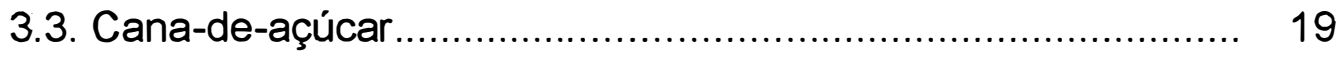

3.3.1. Variedade e mudas .................................................. 19

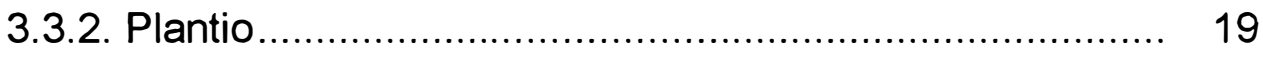

3.3.3. Tratos culturais ........................................................ 20

3.4. Avaliações efetuadas ...................................................... 20

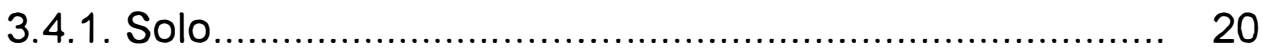

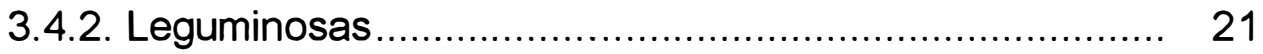

3.4.3. Cana-de-açúcar ....................................................... 21

4. RESULTADOS E DISCUSSÃO …............................................ 22

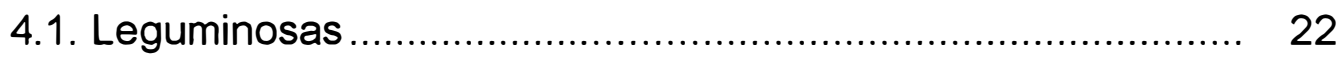

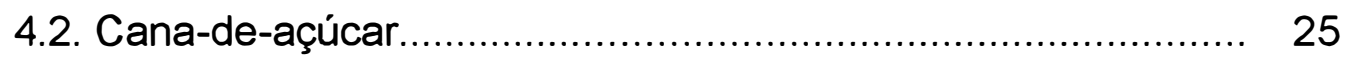

4.2.1. Qualidade da matéria-prima ..................................... 25

4.2.2. Produção agrícola................................................... 27 
4.3. Atributos químicos do solo ............................................... 33

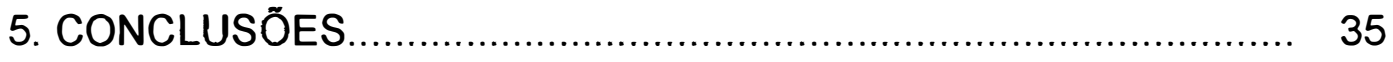

REFERÊNCIAS BIBLIOGRÁFICAS .......................................... 36

BIBLIOGRAFIA RECOMENDADA ............................................ 45 


\section{LISTA DE FIGURAS}

Página

Figura 1 - Produção comparativa de matéria verde e seca entre as espécies testadas como adubos verdes.

Figura 2 - Relação entre produção de matéria seca dos adubos verdes e produtividade da cana-de-açúcar no primeiro corte (t cana/ha em A e t Pol/ha em B).

Figura 3 - Relação entre extração de potássio pela matéria seca dos adubos verdes e produtividade da cana-de-açúcar ( $t$ cana/ha) cultivada subsequentemente, no primeiro corte (A) e na soma dos 3 cortes (B).

Figura 4 - Relação entre extração de cálcio pela matéria seca dos adubos verdes e produtividade da cana-de-açúcar ( $t$ cana/ha) cultivada subsequentemente, no primeiro corte (A) e na soma dos 3 cortes (B). 


\section{LISTA DE TABELAS}

Página

Tabela 1 - Atributos químicos e físicos do solo da área experimental na época do plantio das leguminosas.

Tabela 2 - Características culturais das espécies de leguminosas utilizadas no experimento.

Tabela 3 - Produção de matéria verde e seca (em t/ha), e percentual de matéria seca das leguminosas.

Tabela 4 - Concentração percentual de macronutrientes na matéria seca das leguminosas.

Tabela 5 - Extração de macronutrientes pelas leguminosas (em $\mathrm{kg} / \mathrm{ha}$ ). 25

Tabela 6 - Características tecnológicas da cana-de-açúcar nos 3 cortes avaliados (valores percentuais).

Tabela 7 - Produtividade agrícola dos 3 cortes obtidos, em toneladas de colmos por hectare (TCH) e toneladas de pol por hectare (TPH).

Tabela 8 - Correlação linear entre produção de matéria seca das leguminosas (t/ha) em rotação e produção agrícola ( $\mathrm{TCH}$ e TPH) subsequente de 3 cortes de cana-de-açúcar.

Tabela 9 - Correlação linear entre extração de $\mathrm{K} \mathrm{e} \mathrm{Ca}(\mathrm{kg} / \mathrm{ha})$ pelas leguminosas e produção de cana-de-açúcar (TCH e TPH) cultivada subsequentemente. 
Tabela 10 - Resultados analíticos do solo $(0-25 \mathrm{~cm})$ antes e após o plantio das leguminosas e antes de cada corte da canade-açúcar da área experimental. 


\title{
ADUBAÇÃO VERDE COM LEGUMINOSAS EM ROTAÇÃO COM CANA DE AÇÚCAR (Saccharum spp)
}

\author{
Autor: NEIVALDO TUNES CACERES \\ Orientador: Prof. Dr. JOSÉ CARLOS ALCARDE
}

\section{RESUMO}

Avaliou-se o efeito do cultivo de diferentes espécies de leguminosas como adubos verdes em rotação com cana-de-açúcar, cultivada em solo de baixa fertilidade natural, através de um experimento com 7 leguminosas (Crotalaria juncea L., Crotalaria spectabilis Roth, Cajanus cajan (L) Mill sp - guandu, Mucuna aterrima (Piper e Tracy) Holland - mucuna preta, Mucuna deeringiana (Bort) Merril - mucuna anã, Dolichos lablab L. - lablabe e Canavalia ensiformis D.C. - feijão-de-porco) e uma área em pousio, em uma Areia Quartzosa (Quartzpsamment). As leguminosas foram incorporadas ao solo 115 dias após plantio (em pleno florescimento) e 15 dias após foi efetuado o plantio da cana-de-açúcar, variedade SP70-1143.

A leguminosa mais produtiva foi a $C$. juncea com 7,1 tha de MS sendo seguida pelo guandu (5,5t/ha), feijão-de-porco (5t/ha), C. spectabilis $(4,2 t / h a)$, mucuna anã $(3,9 t / h a)$, lablabe $(3,5 t / h a)$ e finalmente mucuna preta (3t/ha) que teve problemas de germinação. A C. juncea foi também comparativamente a espécie que mais extraiu macronutrientes $(235 \mathrm{~kg} \mathrm{~N}$; 18,5kg P; 101,5kg K; 53,3kg Ca; 29,1 kg Mg e 16,3kg S/ha).

No primeiro corte do canavial houve diferença entre tratamentos, tendo as áreas de crotalária obtido as melhores produções $(133,1$ TCH na $C$. juncea e 133,9 TCH na C. spectabilis), cerca de 15t/ha de diferença em relação aos piores tratamentos que foram o pousio e mucuna preta. No segundo corte esta diferença reduziu para 6,2 t/ha na $C$. juncea e 8,1 t/ha na $C$. spectabilis, desaparecendo no terceiro corte o efeito da adubação verde.

Não houve efeito da adubação verde na qualidade tecnológica (teor de açúcar, pureza e fibra) da cana-de-açúcar em nenhum dos 3 cortes avaliados, nem nos atributos químicos do solo. 


\title{
GREEN MANURE WITH LEGUMES IN CROP ROTATION WITH SUGAR CANE (Saccharum spp)
}

\author{
Author: NEIVALDO TUNES CACERES \\ Adviser: Prof. Dr. JOSÉ CARLOS ALCARDE
}

\section{SUMMARY}

The effect of different species of leguminous cultivated as green manure in crop rotation with sugar cane, in a natural low fertility soil, was evaluated by an experiment with 7 legumes (Crotalaria juncea L., Crotalaria spectabilis Roth, Cajanus cajan (L) Mill sp, Mucuna aterrima (Piper e Tracy) Holland, Mucuna deeringiana (Bort) Merril, Dolichos lablab L. and Canavalia ensiformis D.C.) and an area without cultivation, in a Quartzpsamment soil. The legumes were incorporated in the soil 115 days after planting (in plenary flowering) and 15 days after, sugar cane variety SP70-1143, was planted.

The $C$. juncea was the most produtive legume with $7.1 \mathrm{t} /$ ha of dry matter, being followed by the C. cajan (5.5t/ha), C. ensiformis (5t/ha), C. spectabilis (4.2t/ha), $M$. deeringiana (3.9t/ha), D. lablab (3.5t/ha) and finally the $M$. aterrima ( $3 \mathrm{t} / \mathrm{ha})$, which had trouble in germinating. The $C$. juncea was comparatively the species that extracted more macronutrients through its dry matter (235kg N; $18.5 \mathrm{~kg} \mathrm{P} ; 101.5 \mathrm{~kg} \mathrm{~K} ; 53.3 \mathrm{~kg} \mathrm{Ca} ; 29.1 \mathrm{~kg} \mathrm{Mg}$ and $16.3 \mathrm{~kg} \mathrm{~S} / \mathrm{ha}$ ).

The first harvesting of sugar cane showed differences between treatments, and the crotalarias reached the highest cane production (133.1t/ha in $C$. juncea and 133.9t/ha in C. spectabilis), about 15t/ha more than worse treatments such as the no cultivated area and the $M$. aterrima. In the second harvesting the difference between treatments were reduced to $6.2 \mathrm{t} / \mathrm{ha}$ in the $C$. juncea area and 8.1 tha in the $C$. spectabilis area. In the third, the green manure effect desappeared.

Green manure had no effect in the quality of sugar cane (sugar content, purity and fiber) nor in the chemical soil attributes where green manure with legumes was cultivated. 


\section{INTRODUÇÃO}

A adubação verde é uma prática conhecida desde a antiguidade, podendo ser definida como a incorporação ao solo de material vegetal não decomposto, produzido ou não no local. Desta operação, resultam alterações desejáveis no solo, em seus atributos químicos, físicos e biológicos, levando a cultura subsequente a se beneficiar destas mudanças, refletindo normalmente em maiores produtividades.

Dos benefícios relevantes produzidos pelo uso de leguminosas como adubos verdes, podem ser citados a adição de nitrogênio ao solo; manutenção da matéria orgânica do solo; reciclagem de nutrientes; cobertura do terreno, minimizando problemas com erosão e, em alguns casos, o controle de nematóides e a redução de problemas com a compactação do solo.

A espécie vegetal a ser empregada na adubação verde deve ser, preferencialmente, grande produtora de matéria seca; resistente ao ataque de pragas e moléstias; possuir sementes uniformes e de bom poder germinativo; não ser exigente quanto ao preparo e fertilidade do solo, dispensando o uso de fertilizantes minerais; ser representada por plantas de crescimento rápido, precoce e de fácil incorporação ao solo, e que dispensem tratos culturais. Diversas leguminosas possuem estas características, acrescentando-se ainda a capacidade de fixação do nitrogênio atmosférico pela associação simbiótica de suas raízes com bactérias do gênero Rhizobium.

Cabe ressaltar que, devido a estes atributos, a adubação verde é predominantemente direcionada para áreas de baixa fertilidade natural, ou cujo solo sofreu intensa degradação por uso inadequado.

A cultura da cana-de-açúcar conduzida na região centro-sul do Brasil possui grande afinidade com a adubação verde, uma vez que quando o canavial é reformado, normalmente após o quarto ou quinto corte, o solo permanece desprovido de vegetação por vários meses, sendo frequente a 
ocorrência de elevadas precipitações pluviométricas neste período, tornando bastante severos os problemas decorrentes de erosão.

Os canavicultores consideram a proteção do solo como um dos fatores que mais influenciam no plantio de leguminosas entre um ciclo e outro da cultura, sem menosprezar, contudo, as maiores produtividades observadas em canaviais instalados em áreas onde se empregou tal prática.

Diversas leguminosas prestam-se bem ao uso como adubos verdes em solos cultivados com cana-de-açúcar, sendo a mais utilizada a Crotalaria juncea L.. Esta leguminosa possui grande aceitação entre os agricultores, chegando a tornar difícil a obtenção de suas sementes no mercado por ocasião de sua melhor época de plantio, que ocorre entre os meses de setembro e novembro, em detrimento, muitas vezes, da disponibilidade de outras espécies que também seriam indicadas para as mesmas condições.

Observa-se, na verdade, que há insuficientes informações científicas que embasem recomendações de utilização de outras espécies de leguminosas como adubos verdes, aliadas a poucos dados que mostrem os benefícios econômicos dessas espécies, que justifiquem a adoção desta técnica nos solos cultivados, em especial os cultivados com cana-de-açúcar.

Diante deste panorama, conduziu-se um experimento de campo que objetivou avaliar diferentes espécies de leguminosas indicadas para adubação verde, em um solo de baixa fertilidade natural, durante o período que compreendia a reforma do canavial, possibilitando a comparação dos efeitos obtidos decorrentes do cultivo de diferentes leguminoșas nos atributos do solo, especialmente os químicos, e o reflexo destas no desempenho do canavial instalado após a incorporação das espécies estudadas. 


\section{REVISÃO DE LITERATURA}

\subsection{Aspectos gerais da adubação verde}

A época exata em que a prática da adubação verde teve início é obscura, havendo evidências que era praticada na China antes da dinastia Chou (1134-247aC). Quinhentos anos antes do nascimento de Cristo, há passagens em que autores chineses referem-se ao poder fertilizante de determinadas espécies de Phaseolus quando incorporadas ao solo, classificando seus efeitos como tão bons quanto os proporcionados por excrementos de bicho-da-seda ou esterco curtido (PIETERS, 1927). Posteriormente, filósofos da Antiguidade como Teofrástus na Grécia e Varrão, Catão, Columela e Plínio em Roma, também preconizavam o enterrio de feijões por ocasião de seu florescimento, como prática de melhoria de solos desgastados pelo cultivo intensivo.

Apesar da inexistência de literatura voltada à agricultura durante a idade média, é de se acreditar que a prática do enterrio de leguminosas tenha persistido na Europa durante este período.

KIEHL (1960) salienta que foram necessários mais de dois milênios para que o homem entendesse cientificamente, através do desenvolvimento da química e da microbiologia, o que se conhecia de forma empírica desde tempos remotos.

No Brasil, um dos primeiros trabalhos sobre adubação verde foi feito por DUTRA (1919), que já destacava que o êxito de tal prática estava intimamente ligado à escolha da espécie a ser utilizada, à natureza da cultura que se deseja beneficiar e às diversas circunstâncias naturais e econômicas regionais.

Durante algum tempo, a adubação verde foi considerada simplesmente como a condução de uma cultura de leguminosas plantada no 
verão que deveria ser incorporada ao solo por ocasião do seu florescimento, impedindo, por consequência, a utilização da área por uma cultura que pudesse ser explorada economicamente. Isto limitava totalmente a difusão do emprego do adubo verde para melhoria da produtividade do solo, apesar dos evidentes resultados positivos na cultura econômica que a sucedia, fazendo com que se desenvolvessem estudos abordando adubos verdes cultivados no inverno, contornando assim este problema (MIYASAKA et al., 1984).

Embora se considere de maneira generalizada a adubação verde como sendo a incorporação ao solo de material vegetal fresco, tratandose indiferentemente gramíneas ou leguminosas, mostram-se estas últimas mais apropriadas para tal finalidade, principalmente pelo fato de fixarem nitrogênio do ar, através de bactérias do gênero Rhizobium, que se associam simbioticamente às suas raízes, formando nódulos e enriquecendo o solo com este nutriente. Além disso, podem ser citadas sua riqueza em compostos orgânicos nitrogenados e a presença de um sistema radicular geralmente bem ramificado e profundo (MIYASAKA et al. 1984).

A família das leguminosas é constituída por numerosas espécies que apresentam grande diversificação quanto ao hábito de crescimento, porte, produção de massa e adaptação ao clima e a diferentes tipos de solos, podendo ser particularizada a recomendação de uma determinada espécie para cada condição específica de exploração.

A escolha da leguminosa recai preferencialmente sobre as que produzem maior volume de matéria seca, as menos sujeitas a pragas e moléstias, as que possuem sementes relativamente uniformes e fáceis de serem semeadas com máquina (MIYASAKA et al., 1984).

As leguminosas mais utilizadas em nossas condições são as dos gêneros Crotalaria, Lathyrus, Cajanus, Dolichos e Canavalia, entre outras, ressaltando entre estes gêneros as espécies Crotalaria juncea, C. spectabilis, C. paulina, Mucuna aterrima, $M$. deeringiana, Phaseolus vulgaris, $P$. angustifolia, Glycine max, Lathyrus sativus, Cajanus cajan, Dolichos lablab e Canavalia ensiformis (AGUIAR, sd e MIYASAKA et al., 1984).

São bastante numerosos os trabalhos comparando 0 desempenho destas espécies em condições específicas, sendo frequente a superioridade das crotalárias, como observaram CARDOSO (1956), KIEHL 
(1959), GLÓRIA et al. (1980), MANHÃES \& CRUZ FILHO (1983), MAGALHÃES et al. (1991) e VITTI et al. (1992), apesar de existirem trabalhos que mostram produções semelhantes de crotalárias e outras leguminosas, conforme descrito por CORDEIRO et al. (1983a, b), RIBEIRO (1991) e SILVA (1992).

Os estudos com adubos verdes normalmente são associados a avaliações de seus efeitos nos atributos do solo, bem como a influência destes na produtividade de culturas, sendo estes aspectos aprofundados nos itens que se seguem.

\subsection{Efeitos da adubação verde sobre os atributos do solo}

\subsubsection{Efeito sobre os atributos químicos}

A incorporação de adubos verdes no solo pode proporcionar, dependendo das condições, diversos efeitos como: aumentos no teor de matéria orgânica e maior disponibilidade de $\mathrm{N}$ e outros nutrientes; redução temporária da disponibilidade de $\mathbf{N}$; redução da lixiviação e aumento da nitrificação e da desnitrificação; concentração dos nutrientes na camada arável. A adubação verde usualmente não afeta todas estas reações do solo simultaneamente, e algumas vezes podem nem mesmo vir a ocorrer (WESTCOTT \& MIKKELSEN, 1987).

MUZZILI (1986) lembra que, à exceção do nitrogênio, cuja maior parte é fixada do ar a partir da simbiose, os demais nutrientes são retirados do próprio solo $\mathrm{e}$, portanto, as quantidades incorporadas pela adubação verde não devem ser consideradas como adição de nutrientes ao solo. Contudo, pelos efeitos de reciclagem e mobilização dos nutrientes de formas pouco assimiláveis para formas mais disponiveis às culturas comerciais, associadas a outros benefícios proporcionados pela adubação verde na melhoria da produtividade do solo, mostram que a prática vem constituir um excelente complemento da adubação mineral em solos com limitações sérias de fertilidade.

NOGUEIRA et al. (1989) observaram incrementos nos teores de matéria orgânica e cálcio de um solo aluvial, onde se utilizou Crotalaria juncea L. como adubo verde, contrariando parcialmente os resultados obtidos 
por VITTI et al. (1979) que, utilizando cinco diferentes espécies de leguminosas como adubos verdes, verificaram aumentos nos teores de matéria orgânica, alumínio e hidrogênio do solo, em contrapartida a uma redução nos teores de bases trocáveis ( $\mathrm{Ca}, \mathrm{Mg}$ e $\mathrm{K}$ ), $\mathrm{P}$ e $\mathrm{pH}$ do solo.

YADOV et al. (1986) encontraram aumentos nos teores de matéria orgânica e $\mathrm{N}$ do solo após 6 ciclos de utilização de adubação verde com Crotalaria juncea plantada em anos alternados entre a colheita e o replantio de cana-de-açúcar, propiciando inclusive a obtenção de altas produções de cana durante os 12 anos de cultivo intensivo.

LI (1983) observou a elevação de 0,16\% no teor de matéria orgânica de um solo cultivado com adubos verdes intercalares à cultura da cana-de-açúcar, além de incrementos nos teores disponiveis de N, P e K.

Elevações anuais nos teores de matéria orgânica do solo da ordem de 0,04 a $0,06 \%$, foram observadas por ZHANG (1987) quando incorporou ervilhaca e centeio como adubos verdes na rotação cereal-adubo verde-algodão, ao passo que na rotação algodão-algodão-trigo, observou-se redução em $0,02 \%$.

BADANUR et al. (1990), estudando o efeito da adição de materiais orgânicos em um vertissolo, observaram aumentos para o carbono orgânico e, nitrogênio e fósforo disponíveis com Leucaena leucocephala e Crotalaria juncea incorporadas ao solo nas quantidades de 5t/ha. Já HUSSAIN et al. (1987), que trabalharam em vasos com L. leucocephala e Sesbania bispinosa em doses equivalentes a 5, 10, 15 e 20t/ha de MS, constataram, em todas as doses, significativas reduções no $\mathrm{pH}$ e aumentos na matéria orgânica do solo.

Entretanto, não são raros os estudos onde as alterações de ordem química nos solos são inexpressivas ou inexistentes, como em ANDRADE (1982), que não observou efeito da adubação verde com C. Juncea nos teores de carbono, matéria orgânica, alumínio trocável, fósforo assimilável e potássio trocável; observando apenas uma diminuição no $\mathrm{pH}$ do solo. Também WUTKE \& ALVAREZ (1968) não observaram enriquecimento de carbono e nitrogênio do solo quando se utilizou $C$. juncea como adubo verde.

ARMY \& HIDE (1959) estudaram a influência da adubação verde anual com trevo (Trifolium spp), ervilhaca (Vicia villosa Roth) e Lollium 
spp durante quatro anos e não observaram alterações nos teores de carbono e nitrogênio do solo.

Também não foi detectada por BULISANI et al. (1972) influência da adubação verde com soja perene (Glycine wightii Verdc.) e capim gordura (Melinis minutiflora Beauv) no teor de carbono de um latossolo vermelho escuro fase rasa, após quatro meses de suas incorporações. TANAKA et al. (1981) também não observaram diferenças no teor de matéria orgânica de um latossolo vermelho escuro textura média, quatro meses após a incorporação de C. juncea, Cajanus cajan, Mucuna aterrima e Canavalia ensiformis.

Algumas vezes, no entanto, a adubação verde, se não mostra elevação nos teores de matéria orgânica do solo, apresenta um efeito de manutenção de seus teores nos solos em que esta prática é adotada, como foi observado por COPE et al. (1958) em um solo silte-arenoso que, após 30 anos de utilização de ervilhaca (Vicia villosa Roth) como adubo verde em rotação com algodão e milho, manteve o nível de carbono total do solo quando comparado ao nível inicial, em contrapartida ao decréscimo deste teor onde a adubação verde esteve ausente. BONFILS (1963) também observou a preservação dos teores iniciais de nitrogênio total e matéria orgânica de um solo arenoso onde se utilizou a adubação verde.

\subsubsection{Efeito sobre os atributos físicos}

O efeito da adubação verde sobre os atributos físicos do solo pode ser encarado exclusivamente como resultante do incremento da matéria > orgânica do solo. Como visto no ítem anterior, os adubos verdes nem sempre contribuem na elevação deste teor determinado analiticamente, não sendo, portanto, uma constante a relação entre adubação verde e alterações de ordem física nos solos.

Os adubos verdes ainda em desenvolvimento, previamente à incorporação, exercem uma presença marcante sobre a proteção do solo, principalmente nas camadas superficiais, contra os fatores ambientais, sobretudo radiação solar e impacto das gotas de chuva, que destroem os agregados do solo promovendo a obstrução dos poros superficiais pelo 
acúmulo de argilas, resultando na redução da capacidade de infiltração de água no solo, favorecendo o escorrimento horizontal do excesso de água. Esta proteção afeta sensivelmente a amplitude de variação térmica, armazenamento e evaporação de água do solo e perdas por erosão.

MIYASAKA et al. (1966a) observaram em estudo de adubação verde com soja perene e capim gordura incorporados, a redução da amplitude de variação térmica do solo de $35^{\circ} \mathrm{C}$ para $17^{\circ} \mathrm{C}$, refletindo no aumento do teor de água do solo e na produtividade do feijão.

Estudando o efeito de quinze espécies de adubos verdes na capacidade de retenção de água em um latossolo vermelho escuro sob cerrado, RESCK et al. (1982) observaram elevações médias de $0,21 \mathrm{~cm}^{3}$ para $0,26 \mathrm{~cm}^{3}$ de água $/ \mathrm{cm}^{3}$ de solo para todos os adubos verdes testados.

NOGUEIRA et al. (1989) observaram reduções na densidade do solo com consequente aumento na porosidade de um solo aluvial textura argilosa após o cultivo e incorporação de Crotalaria juncea.

MACRAE \& MEHUYS (1987), trabalhando com solos argiloso e arenoso no Canadá, verificaram que a adubação verde no solo argiloso aumentou a distribuição de agregados secos e reduziu a densidade, mas não aumentou a estabilidade de agregados em água e a infiltração de água. No solo arenoso, nenhum parâmetro físico analisado no solo que recebeu adubo verde diferiu do tratamento com monocultura de milho.

OLSEN \& JONES (1989) estudando a recuperação de solos decapitados (sem o horizonte superficial), observaram que a adubação verde promoveu aumentos no teor de matéria orgânica dos solos, porém com um modesto efeito sobre a densidade da camada de 0 a $30 \mathrm{~cm}$, que apesar de tudo, recuperou a capacidade produtiva, comparável à de solos não erodidos.

ANDRADE (1982) não constatou efeito da adubação verde e da incorporação de resíduos de desfibramento de $C$. juncea sobre a porosidade total de uma terra roxa estruturada, observando apenas uma diminuição significativa na densidade do solo, assim mesmo temporária.

Também não foram observados efeitos marcantes nas propriedades físicas de um solo arenoso de origem vulcânica, estudado por RAMUNNI et al. (1987), com a utilização de adubação verde, uma vez que esta foi rapidamente mineralizada. 
O uso de leguminosas na recuperação de solo para cana-deaçúcar não promoveu modificações nas características físicas do solo, conforme citam WUTKE \& ALVAREZ (1968).

\subsubsection{Efeito sobre os atributos biológicos}

Assim como os atributos físicos do solo, a atividade biológica é afetada pela adubação verde devido ao efeito exercido sobre a matéria orgânica do solo que, por sua vez, supre os microrganismos presentes com as substâncias orgânicas e inorgânicas necessárias ao seu desenvolvimento, estabelecendo a partir da natureza do material vegetal adicionado, um maior desenvolvimento de determinados organismos microbianos, intensificando processos bioquímicos, que resultam na melhoria da capacidade produtiva dos solos. Esta melhoria provém desde a liberação de nutrientes antes indisponíveis, melhoria na absorção de nutrientes e água devidos a fungos micorrízicos, até a melhoria das condições físicas do solo pela proliferação de minhocas, como comprovou SCHAAFFHAUSEN (1968), através da adição de leguminosas como adubos verdes na tentativa de recuperar economicamente solos de regimes tropicais.

A incorporação de adubos verdes em um solo salino levou ZHANG (1987) a observar a melhoria das propriedades químicas e físicas do solo, resultando num grande aumento da atividade microbiológica.

MIYASAKA et al. (1966a) observaram que a incorporação ao solo de massa vegetal não decomposta de leguminosas e gramíneas levou a uma tendência de formação de maior número de nódulos em raizes de feijoeiro, principalmente quando a incorporação era realizada com gramíneas.

Já ANDRADE (1982) não observou efeito na atividade microbiana do solo quando incorporou $C$. juncea como adubo verde ou como resíduo de desfibramento, desde a incorporação da massa vegetal até quatro meses após.

Outro importante efeito exercido por determinadas espécies utilizadas como adubos verdes é no controle de nematóides. RESCK et al. (1982) observaram que todos os tratamentos de adubos verdes diminuíram drasticamente a população de nematóides na cultura da soja, cultivar UFV-1. 
Também CURI \& SILVEIRA (1978) observaram o controle de nematóides do gênero Meloidogyne, na cultura da soja, similar aos tratamentos químicos com aldicarb e phenamiphos, onde se realizou rotação de cultura com mucuna-preta intercalar ao milho. Os autores atribuem a melhor produção de soja proporcionada pela rotação com mucuna-preta à sua ação intrínseca de má hospedeira ao nematóide, ou de indiretamente propiciar condições melhores a organismos antagônicos a nematóides, e ainda pela sua ação no sentido de melhoria das condições físicas e químicas do solo.

CURI et al. (1979) observaram que a produção de algodão IAC16 no tratamento onde se empregou rotação com milho consorciado com mucuna-preta foi similar aos tratamentos que utilizaram controle químico de nematóides Rotylenchulus reniformis com aldicarb, carbofuran e fensulfothion, que por sua vez foram estatisticamente superiores à testemunha.

Exemplos similares são apresentados por KAGE (1984) em relação ao controle de nematóides nas culturas de algodão e soja na região paulista da Alta Mogiana, localizada ao norte do estado.

Deve-se atentar para o fato de que nem todas as espécies utilizadas como adubos verdes controlam nematóides, como cita PIAMONTE (1992) em relação ao lablabe, que é hospedeiro de nematóides e inviabiliza a rotação com plantas sensiveis a essa praga.

MACEDO \& BOTELHO (1995) avaliando os efeitos de seis espécies de leguminosas sobre a população de nematóides e cupins, e a produção de cana-de-açúcar, concluíram que a Crotalaria juncea reduziu a população de cupins e a $C$. spectabilis inibiu a população de nematóides. Quando associadas à heptacloro aumentaram a produção de cana, tendo o conjunto $C$. spectabilis - heptacloro obtido as melhores produções na média de 4 cortes.

NOVARETTI et al. (1977) estudaram a contribuição do uso de C. spectabilis no controle de nematóides em cana-de-açúcar e observaram, contrariamente, aumentos populacionais de nematóides dos gêneros Ditylenchus, Helicotylenchus e nematóides de vida livre, e manutenção das populações de nematóides dos gêneros Aphelenchoides, Criconemoides, Meloidogyne e Trichodorus. 


\subsection{Resposta de culturas à adubação verde}

\subsubsection{Culturas diversas}

Os primeiros estudos no Brasil envolvendo adubação verde confundem-se com a rotação de culturas com leguminosas, uma vez que se perdia um ano agrícola com o cultivo de adubos verdes. Apesar de tudo, resultados irrefutáveis do benefício desta prática já eram conseguidos em diversas culturas, como os analisados por YATES (1952), em relação a um estudo de rotação de culturas de oito anos, que concluiu que a melhor produção de algodão foi obtida quando esta seguia uma plantação consorciada de milho e mucuna, chegando a produzir até $133 \%$ mais que no tratamento com plantio contínuo.

Muitos trabalhos das décadas de 40 e 50, mostrando o benefício da rotação com adubos verdes em diversas culturas, são apresentados por MIYASAKA et al. (1984), sendo que posteriormente a esta época são mais frequentes os estudos envolvendo esta prática de modo a não comprometer o plantio de culturas de interesse econômico, seja pelo cultivo intercalar consorciado, adequação entre épocas de plantio, ou utilização de culturas de inverno, como o realizado por MIYASAKA et al. (1966b) com feijão "da seca", que na média de quatro experimentos, observou incrementos entre 42 e $50 \%$ na produção de feijão, utilizando como adubos verdes lablabe, tefrósia e guandu, e um aumento médio de $85 \%$ quando se utilizou a C. juncea.

Estudando o efeito da adição de materiais orgânicos sobre a sequência feijão-milho-feijão, ABBOUD \& DUQUE (1986) observaram que a primeira produção de feijão aumentou com a incorporação de $C$. juncea, sendo a produção seguinte de milho maior quando se empregou mucuna-preta, não se observando efeito residual na subsequente cultura de feijão.

DE-POLLI \& CHADA (1989), estudando o efeito da adubação verde com mucuna-preta, C.juncea e feijão-de-porco, incorporadas ou em cobertura, cultivadas no inverno durante quatro anos entre ciclos de milho, observaram que a melhor produção de milho foi com feijão-de-porco incorporado, afirmando ainda ser uma prática conservacionista altamente viável, possibilitando produtividade até quatro vezes maior que a do controle. 
Estudando a influência da recuperação do solo com adubação verde de inverno nas respostas à adubação nitrogenada na cultura do milho, MUZZILI et al. (1983) constataram que a adubação verde foi boa alternativa para recuperação da capacidade produtiva do solo e contribuiu para reduzir gastos com fertilizante nitrogenado, aumentando em cerca de $26 \%$ a produção da cultura. Observaram também que a cultivar Cateto Prolífico não respondeu à adubação nitrogenada, mas reagiu favoravelmente à adubação verde de inverno, e as cultivares AG-162, C-501 e Piranão evidenciaram acentuada resposta à adubação nitrogenada, mas a prática de adubação verde de inverno supriu a sua demanda em nitrogênio.

BELLINGIERI et al.(1989) observaram melhoras significativas na produção de grãos e conteúdos de nitrogênio e proteína do milho, quando Lablab purpureus foi incorporado nas entrelinhas da cultura, antes do seu florescimento.

HUSSAIN et al. (1987), reportando-se a um experimento em vasos que comparou o crescimento de milho em um solo barro argilo arenoso, com ou sem adição de NPK ou folhas secas de Leucaena leucocephala ou Sesbania bispinosa, em doses de 5, 10, 15 e 20t/ha, observaram que todas as doses de adubos verdes aumentaram significativamente a produção de milho, sendo o maior aumento proporcionado por $15 t / h a$ de folhas de $L$. leucocephala ( 3,5 vezes a produção do controle). Os adubos verdes tiveram ainda efeito residual sobre a cultura do trigo, cultivado subsequentemente.

HUANG (1984), estudando efeitos da adubação verde na China, observou incrementos entre 14 e $18 \%$ na produção de milho, e entre 16 e $20 \%$ na produção de trigo.

RACHHPAL-SINGH et al. (1982) estudaram a substituição do nitrogênio com três adubos verdes (caupi, Cyamposis tetragonoloba e Sesbania aculeata) na rotação milho-trigo, e verificaram que as produções de grãos de milho com caupi ou C. tetragonoloba, como adubos verdes, e 50kg/ha de $\mathrm{N}$, ou $\mathrm{S}$. aculeata e $75 \mathrm{~kg} / \mathrm{ha}$ de $\mathrm{N}$, foram similares à obtida com $125 \mathrm{~kg} / \mathrm{ha}$ de N. Observaram ainda efeito residual na produção de grãos de trigo, cultivado em seguida, para os três adubos verdes testados.

GONÇALVES (1985) também observou efeito benéfico da incorporação de lablabe, independentemente do estado de desenvolvimento 
(florescimento, frutificação e maturação), sobre a sucessão girassol-amendoim, sendo inicialmente observado um aumento médio de $70 \%$ na produção de grãos de girassol, em relação à testemunha, e posteriormente, aumento médio de $23 \%$ para a produção de grãos de amendoim, tendo sido ainda verificado efeito positivo da incorporação do lablabe ao solo no peso de cem sementes e qualidade fisiológica das sementes de girassol.

Em relação à soja, GAUDÊNCIO et al. (1988) observaram aumentos na produção de grãos de soja cultivada continuamente no verão, quando esta era alternada com adubação verde de inverno com Lupinus /uteus.

SARAVANAN et al. (1987), trabalhando com arroz irrigado na Índia, verificaram que a incorporação de adubos verdes, mais $45 \mathrm{~kg} / \mathrm{ha}$ de $\mathrm{N}$, era mais eficiente que $90 \mathrm{~kg} / \mathrm{ha}$ de $\mathrm{N}$, como uréia, para produção de arroz em casca.

Trabalhando com adubos verdes em um vertissolo da Índia, BADANUR et al. (1990) verificaram que a incorporação de 5 t/ha de $C$. juncea propiciou produção de sorgo superior à obtida com $50 \mathrm{~kg}$ de $\mathrm{N}$ e $25 \mathrm{~kg}$ de $\mathrm{P}_{2} \mathrm{O}_{5} /$ ha, que por sua vez foi igual à obtida com 5t/ha de Leucaena leucocephala.

RIBEIRO (1991), estudando a influência do estado fenológico da $C$. juncea e mucuna-preta sobre a decomposição da fitomassa e seu efeito fertilizante, verificou que as fitomassas da crotalária em pré-floração e floração incrementaram a produção de matéria-seca de painço, principalmente após 30 e 45 dias da incorporação. A mucuna-preta também promoveu maior produção de painço, sem contudo ter havido diferença entre as diversas épocas de incorporação. A crotalária, na floração, provocou a maior absorção de nitrogênio pelo painço, enquanto que entre as fitomassas de mucuna não houve diferença.

NOGUEIRA et al. (1989), avaliando o efeito do gesso, fosfato natural e adubo verde com $C$. juncea na cultura do alho, em um solo aluvial de Cambuquira-MG, constataram um aumento significativo de $647 \mathrm{~kg} / \mathrm{ha}(9 \%)$ na produção de alho devido ao uso do adubo verde, sendo inclusive, comparativamente, o tratamento que contribuiu para o maior aumento da produtividade. 
Investigando o efeito da mucuna-preta e C. juncea, como adubo verde, na disponibilidade de fósforo proveniente de fosfato-de-rocha (patos-de-minas) e termofosfato na cultura de aveia seguida de feijão, SILVA et al. (1985) concluiram que a mucuna foi mais eficiente que a crotalária na utilização de fósforo do fosfato de patos-de-minas, tendo sido ainda observados efeitos benéficos da adubação verde na produção de massa seca de aveia e na produção de grãos de feijão, que propiciaram em média aumentos de 21 e $81 \%$, respectivamente.

\subsubsection{Cana-de-açúcar}

A cultura da cana-de-açúcar, desenvolvida na região CentroSul do Brasil, possui duas épocas principais de plantio, compreendendo lavouras que desenvolvem seu primeiro ciclo durante 12 ou 18 meses. No ciclo de 12 meses, também conhecido como "cana-de-ano", o plantio é efetuado entre os meses de agosto e outubro, dependendo da microregião, sendo o corte do canavial efetuado já no ano seguinte. Na cana-planta de ciclo de 18 meses, ou "ano-e-meio", o plantio é realizado, principalmente, entre os meses de fevereiro e abril, adaptando-se perfeitamente à prática da adubação verde com leguminosas desenvolvidas no verão, plantadas após o último corte do canavial a ser reformado.

Esta prática torna-se particularmente importante pela proteção que exerce sobre o solo durante uma época do ano em que ocorrem precipitações pluviométricas de grande intensidade que, sobre um terreno desprotegido, podem causar erosão bastante severa. Também a cobertura vegetal neste período reduz o desenvolvimento de plantas daninhas.

Diversos trabalhos abordando o uso da adubação verde em canaviais foram desenvolvidos nos últimos quarenta anos, havendo quase unanimidade em relação ao benefício desta prática para a cultura da cana-deaçúcar.

CARDOSO (1956) observou, em diversos experimentos de campo, que a Crotalaria juncea destacava-se de outras leguminosas, propiciando os melhores efeitos sobre a produtividade de canaviais de primeiro corte, obtendo na média de cinco ensaios, ganhos de produtividade da ordem 
de $15 \%$. Observou, ainda, que a ação exercida pela adubação verde era bastante efêmera, não se verificando efeito residual sobre os cortes subsequentes.

Um dos raros resultados inócuos da adubação verde sobre cana-de-açúcar foi obtido por WUTKE \& ALVAREZ (1968), os quais não observaram efeito da $C$. juncea e adubação nitrogenada, quando em presença de calagem, chegando a observar efeitos depressivos destes tratamentos quando o calcário não foi empregado.

CAMPOS (1977) testando Crotalaria juncea e lablabe como adubos verdes em rotação entre um ciclo e outro da cultura da cana-de-açúcar, obteve aumentos médios, em 3 cortes, de $20 \%$ com o uso de Crotalaria juncea e $26 \%$ com lablabe, apesar da produção de matéria verde da crotalária ter sido em média superior à da lablabe, 12,8t/ha contra 7,3 t/ha.

Dois experimentos envolvendo competição de leguminosas para utilização como adubos verdes, em áreas canavieiras da região CentroSul do Brasil, apontam como melhores opções a Crotalaria juncea (GLÓRIA et al., 1980) e C. juncea, C. spectabilis e mucuna-preta (MANHÃES \& CRUZ FILHO, 1983). Ambos os trabalhos afirmam ainda que, segundo as análises químicas realizadas, as leguminosas teriam condições de suprir, completa ou parcialmente, o primeiro ciclo da cultura (cana-planta) em nitrogênio e potássio. Fazem, contudo, esta afirmação sem constatação experimental de que realmente a cana-planta não responderia à aplicação destes dois elementos, principalmente em relação ao potássio, uma vez que sua origem no tecido das leguminosas provém, única e exclusivamente, da quantidade previamente existente no solo (MUZZILI,1986). Em relação ao nitrogênio, a afirmação é fundamentada.

ANDRADE (1982) observou que a incorporação de resíduos de C. juncea aumentou a porcentagem e a velocidade de brotação da cana-deaçúcar, apesar de ser um resultado parcial, tendo em vista que não foram obtidas as produções agrícolas dos diferentes tratamentos com adubos verdes, limitando assim as conclusões.

LI (1983) observou incrementos de $11,8 \%$ na produção de cana-de-açúcar em função do uso de adubos verdes intercalares à cultura, e 
atribuiu este aumento à reversão das causas que declinam a fertilidade do solo e o desbalanço de nutrientes.

Após 12 anos de cultivo intensivo de cana-de-açúcar, onde as lavouras eram renovadas em intervalos de dois anos, o plantio de $C$. juncea entre cada segundo corte e o novo plantio possibilitou a manutenção de altas produtividades de cana na Índia, conforme constataram YADOV et al. (1986).

Também na Índia, PANDIT \& JAFRI (1986), testando cinco adubos verdes (Vigna spp) em canaviais, durante 3 anos, observaram apenas no terceiro ano (segunda soqueira) maiores produções onde o adubo verde era incorporado nas entrelinhas.

JAYABAL et al.(1989), comparando o desenvolvimento da cana-de-açúcar cultivada sozinha ou com plantio intercalar de $C$. juncea, Vigna mungo, $V$. unguiculata ou $V$. radiata, incorporadas no local após 45,60 ou 75 dias após o plantio, verificaram que a maior produção de cana foi obtida usando $V$. radiata intercalar, incorporada aos 45 dias. Foi constatado, também, que a qualidade do caldo foi significativamente melhor com o cultivo intercalar, comparado à cultura sozinha.

Na Nova Zelândia, HILL (1989) afirma que a prática da adubação verde resulta em aumentos de produtivididade que proporcinam altos retornos financeiros. 


\section{MATERIAL E MÉTODOS}

\subsection{Local e solo}

O experimento foi instalado em um solo classificado como Areia Quartzosa (Quartzpsament), localizado no distrito de Artemis, município de Piracicaba, sendo seus atributos químicos e físicos apresentadas na tabela 1 :

Tabela 1 - Atributos químicos e físicos do solo da área experimental na época do plantio das leguminosas.

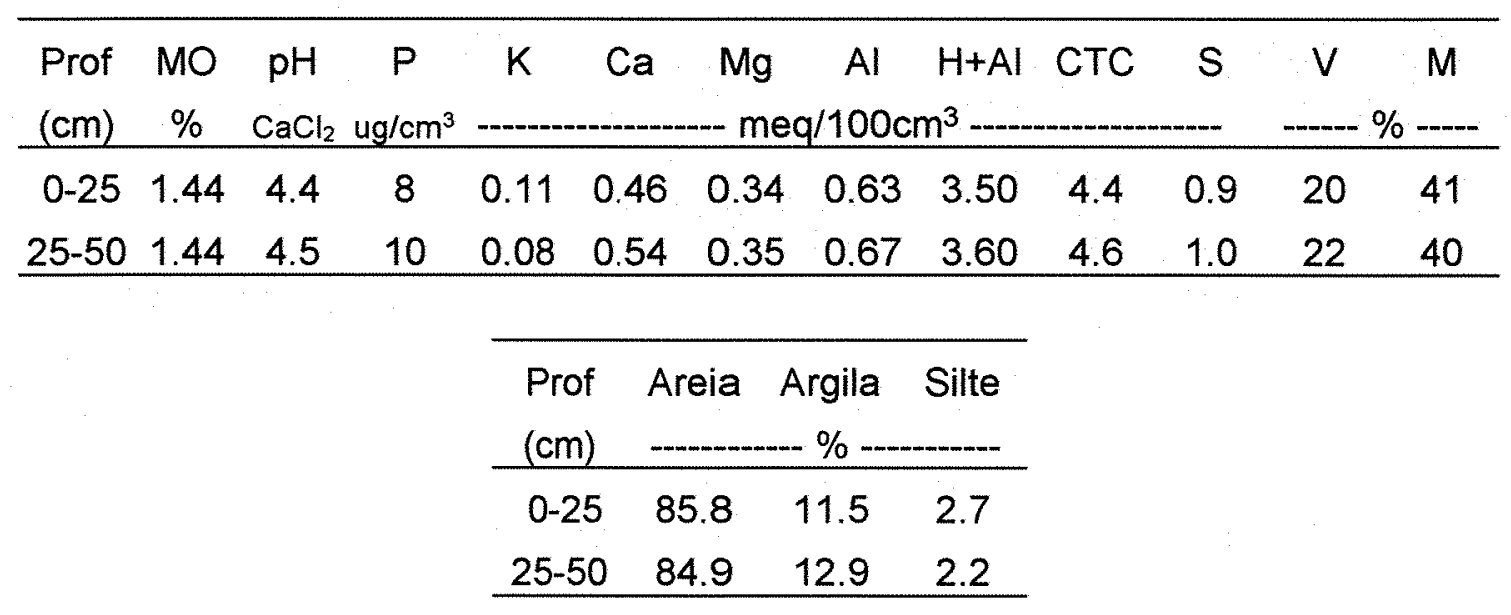

\subsection{Delineamento experimental}

O delineamento experimental adotado foi 0 de blocos casualizados com cinco repetições e oito tratamentos, representados por sete leguminosas e mais uma área em pousio, totalizando 40 parcelas de $20 \mathrm{~m}$ de comprimento por $10 \mathrm{~m}$ de largura, tendo sido esta ocupada por 20 linhas 
espaçadas de $0,5 \mathrm{~m}$ para as leguminosas, que foram sucedidas por 9 linhas de cana-de-açúcar espaçadas de 1,10m.

Os tratamentos foram os seguintes:

- Tratamento 1 - Pousio;

- Tratamento 2 - Crotalaria juncea L.;

- Tratamento 3 - Crotalaria spectabilis Roth;

- Tratamento 4 - Cajanus cajan (L) Millsp - Guandu;

- Tratamento 5 - Mucuna aterrima (Piper e Tracy) Holland - Mucuna-preta;

- Tratamento 6 - Mucuna deeringiana (Bort) Merril - Mucuna-anã;

- Tratamento 7 - Dolichos lablab L. - Lablabe;

- Tratamento 8 - Canavalia ensiformis D.C. - Feijão-de-porco.

As características culturais de cada espécie, obedecidas no plantio das parcelas experimentais, são apresentadas na tabela 2:

Tabela 2 - Características culturais das espécies de leguminosas utilizadas no experimento.

\begin{tabular}{lccc}
\hline \multirow{2}{*}{ Leguminosa } & Espaçamento & \multicolumn{2}{c}{ Sementes necessárias } \\
\cline { 3 - 4 } & $\mathrm{m}$ & $\mathrm{kg} / \mathrm{ha}$ & semente/m \\
\hline C. juncea & 0.5 & 30 & 25 \\
C. spectabilis & 0.5 & 12 & 30 \\
Guandu & 0.5 & 85 & 5 \\
Mucuna preta & 0.5 & 105 & 10 \\
Mucuna anã & 0.5 & 36 & 12 \\
Lablabe & 0.5 & 57 & 12 \\
Feijão-de-porco & 0.5 & 100 & 5 \\
\hline
\end{tabular}

AGUIAR (s.d.)

A semeadura das leguminosas foi efetuada manualmente após a sulcação mecânica do terreno no espaçamento recomendado. As sementes foram separadas em porções individuais, suficientes para $20 \mathrm{~m}$ de sulco, sendo as quantidades baseadas em peso nas Crotalárias, devido ao pequeno tamanho das sementes, e contadas nas demais espécies que possuiam 
sementes de maior tamanho. Isto garantiu uma precisão bastante grande nas quantidades de sementes distribuidas em cada parcela.

O plantio foi efetuado em 31/10/89 visando a incorporação das leguminosas após um período mínimo de desenvolvimento de aproximadamente 110 dias, coincidindo assim com a época mais adequada para o plantiơ da cana-de-açúcar naquelas condições (fevereiro/março).

Não foi efetuada a adubação das leguminosas, uma vez que se objetivava avaliar a adubação verde sob a ótica do menor custo possível de instalação.

Foi informado que a área recebeu, durante o preparo do solo, calcário na dose recomendada pelo critério de saturação por bases, objetivando sua elevação à $60 \%$, contudo observa-se pelos resultados analíticos do solo por ocasião do plantio das leguminosas, que tal objetivo não foi alcançado ou então que o produto não foi utilizado adequadamente.

\subsection{Cana-de-açúcar}

\subsubsection{Variedade e mudas}

Foram utilizadas mudas provenientes de área comercial de primeiro corte da variedade SP70-1143, que apresenta como características alta produtividade; rusticidade, sendo na época em que o experimento foi instalado a variedade mais indicada para plantio em áreas de baixa fertilidade natural; apresentando excelente brotação de soqueiras, propiciando grande longevidade do canavial; florescimento e maturação de média para tardia, com período ideal para colheita entre junho e agosto; alta resistência ao carvão e mosaico, resistente à podridão vermelha, suscetivel à escaldadura e resistente aos nematóides das galhas (COOPERATIVA CENTRAL DOS PRODUTORES DE AÇÚCAR E ÁLCOOL DO ESTADO DE SÃO PAULO, 1983).

\subsubsection{Plantio}

O plantio da cana-de-açúcar foi efetuado 15 dias após a incorporação das leguminosas com grade aradora, tendo ocorrido em 09/03/90, 
utilizando-se espaçamento entre linhas de $1,10 \mathrm{~m}$, distribuindo-se duas canas no sulco de plantio, com densidade de gemas ao redor de 14 gemas $/ \mathrm{m}$, possibilitando assim um adequado estabelecimento do canavial.

A adubação de plantio da cana-de-açúcar foi $500 \mathrm{~kg} / \mathrm{ha}$ da fórmula 04-30-16, correspondendo a 20,150 e $80 \mathrm{~kg} / \mathrm{ha}$ de $\mathrm{N}, \mathrm{P}_{2} \mathrm{O}_{5}$ e $\mathrm{K}_{2} \mathrm{O}$, respectivamente.

\subsubsection{Tratos culturais}

Sessenta dias após o plantio foi efetuada adubação de cobertura com $200 \mathrm{~kg} / \mathrm{ha}$ da fórmula $20-0-30$, correspondendo a $40 \mathrm{~kg}$ de $\mathrm{N}$ e $60 \mathrm{~kg}$ de $\mathrm{K} 2 \mathrm{O} / \mathrm{ha}$. Após os sucessivos cortes do canavial, foram realizados os tratos culturais rotineiros em soqueira, que compreendiam ao aleiramento de palhas, cultivo mecânico, subsolagem, adubação e aplicação de herbicidas.

A adubação utilizada no cultivo das soqueiras foi de $500 \mathrm{~kg} / \mathrm{ha}$ da fórmula NPK 20-05-25, correspondendo à $100 \mathrm{~kg}$ de $\mathrm{N}, 25 \mathrm{~kg}$ de $\mathrm{P}_{2} \mathrm{O}_{5}$ e $125 \mathrm{~kg}$ de $\mathrm{K}_{2} \mathrm{O} / \mathrm{ha}$, respectivamente, após o primeiro corte; e $550 \mathrm{~kg} / \mathrm{ha}$ da fórmula 17-0-30, correspondendo à $95 \mathrm{~kg}$ de $\mathrm{N}$ e $165 \mathrm{~kg}$ de $\mathrm{K} 2 \mathrm{O} / \mathrm{ha}$, respectivamente, após o segundo corte, sendo estas as adubações utilizadas nas áreas comerciais imediatamente ao lado da área experimental.

\subsection{Avaliações efetuadas}

\subsubsection{Solo}

O solo foi amostrado por tratamento antes do plantio da canade-açúcar, após, portanto, à incorporação das leguminosas, e após o primeiro e o segundo corte da cana-de-açúcar, caracterizando assim a condição inicial do solo onde se desenvolveu a cana planta e as duas soqueiras. A amostragem foi efetuada nas entrelinhas da cultura, na profundidade de 0 $25 \mathrm{~cm}$, sendo cada amostra composta por 3 subamostras de cada parcela do tratamento, totalizando 15 subamostras por tratamento. 
As amostras de solo foram submetidas a análise de rotina, determinando-se $\mathrm{pH}$, matéria orgânica, fósforo, potássio, cálcio, magnésio, alumínio e hidrogênio + alumínio, segundo RAlJ et al. (1987).

\subsubsection{Leguminosas}

As produções de matéria verde e seca foram avaliadas através de amostragem realizada imediatamente antes à incorporação, sendo coletadas três amostras por parcela, compreendidas por 2 linhas de $1 \mathrm{~m}$ de comprimento, correspondendo a $1 \mathrm{~m}^{2}$ por amostra. Após pesagem das amostras individuais, estas foram agrupadas por parcela e trituradas em picador de forragens, sendo coletada uma alíquota de aproximadamente $500 \mathrm{~g}$, que, acondicionada em saco de papel, foi posteriormente seca em estufa à $60-65^{\circ} \mathrm{C}$, até peso constante, possibilitando assim a determinação de produção de matéria seca.

As amostras de material vegetal seco foram então submetidas a análise química para determinação dos teores de macronutrientes.

\subsubsection{Cana-de-açúcar}

$\mathrm{Na}$ cana-de-açúcar foi efetuada a avaliação de produção de colmos e açúcar por hectare. Todos os cortes foram efetuados manualmente, sem o desponte, após a queima da palha. A pesagem das parcelas foi efetuada através de célula de carga ( $1{ }^{\circ}$ corte) e dinamômetro (demais cortes) acoplados ao braço da carregadeira de cana, apenas das cinco linhas centrais, que compreendiam a parcela útil, ficando as outras 4 (duas de cada lado) constituindo a bordadura.

Após a pesagem das parcelas, retirou-se aleatoriamente 10 colmos por parcela para compor uma amostra para análise tecnológica da matéria-prima, sendo determinados brix, leitura sacarimétrica e peso do bolo úmido (PBU), possibilitando à partir destas o cálculo da pureza, fibra e teor de sacarose, segundo metodologia descrita em COOPERATIVA CENTRAL DOS PRODUTORES DE AÇÚCAR E ÁLCOOL DO ESTADO DE SÃO PAULO (1980). 


\section{RESULTADOS E DISCUSSÃO}

\subsection{Leguminosas}

A tabela 3 mostra os dados de produção de matéria seca e verde das leguminosas avaliadas, tendo as crotalárias, juntamente com o feijão-de-porco e a mucuna anã, nesta ordem, obtido as maiores produções de matéria verde, sendo seguidas com diferença estatística pelo guandu, mucuna preta e lablabe. Contudo, em termos de produção de matéria seca, a Crotalaria juncea superou as demais espécies produzindo $7,1 \mathrm{t}$ de matéria seca/ha (Figura 1). Estes resultados concordam com os obtidos por GLÓRIA et al. (1980), MANHÃES \& CRUZ FILHO (1983), MAGALHÃES et al. (1991) e VITTI et al. (1992), estes últimos que testaram as mesmas espécies aqui estudadas em adubação verde intercalar à cultura de citrus.

Tabela 3 - Produção de matéria verde e seca (em t/ha), e percentual de matéria seca das leguminosas.

\begin{tabular}{lcccc}
\hline \multicolumn{1}{c}{ Leguminosa } & matéria verde & matéria seca & $\%$ mat. seca \\
\hline C. juncea & $22.5 \mathrm{a}$ & $7.1 \mathrm{a}$ & 31.7 \\
C. spectabilis & $21.6 \mathrm{a}$ & $4.2 \mathrm{c}$ & 19.7 \\
Guandu & $16.5 \mathrm{~cd}$ & $5.5 \mathrm{~b}$ & 33.0 \\
Mucuna preta & $15.1 \mathrm{~d}$ & $3.0 \mathrm{~d}$ & 20.0 \\
Mucuna anã & $18.5 \mathrm{bc}$ & $3.9 \mathrm{c}$ & 20.9 \\
Lablabe & $14.5 \mathrm{~d}$ & $3.5 \mathrm{~cd}$ & 24.1 \\
Feijão-de-porco & $21.0 \mathrm{ab}$ & $5.0 \mathrm{~b}$ & 23.7 \\
\hline dms Duncan $5 \%$ & $3.0^{* *}$ & $0.7^{* *}$ & - \\
\hline
\end{tabular}

Médias seguidas da mesma letra não diferem estatisticamente pelo teste de Duncan, ao nível de $5 \%$ de probabilidade. 


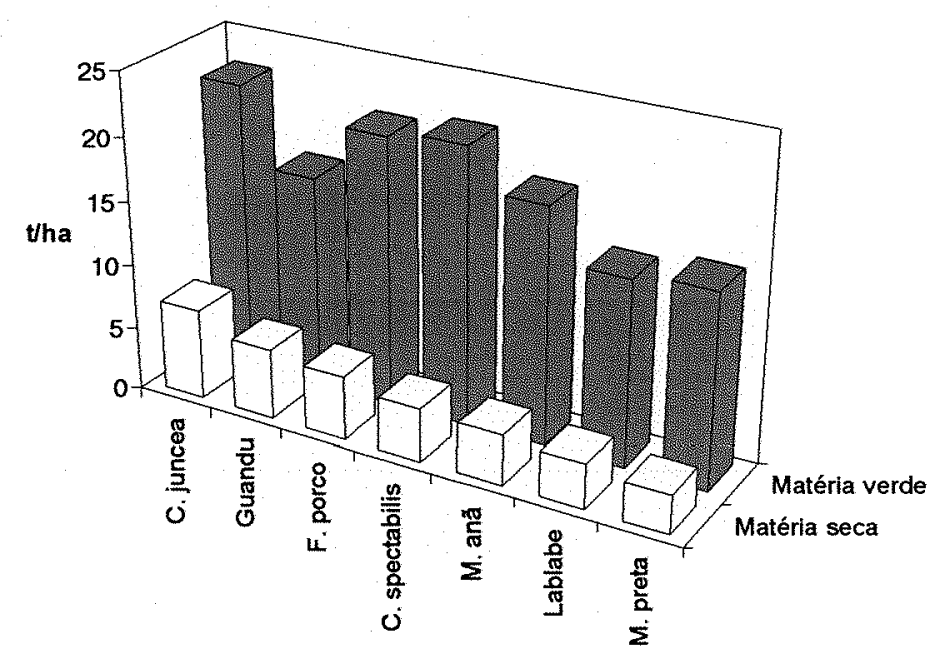

Figura 1 - Produção comparativa de matéria verde e seca entre as espécies testadas como adubos verdes.

A mucuna preta foi a espécie menos produtiva, com $3,0 t /$ ha de matéria seca. Observou-se que houve problema na germinação desta leguminosa, que atingiu uma densidade de plantas abaixo do esperado por ocasião da incorporação. A dormência das sementes pode explicar em parte este problema, que foi ainda confirmada pela presença de plantas desta espécie ao longo de toda a duração do experimento. Como a incorporação ocorreu antes da maturidade fisiológica das sementes produzidas, 0 aparecimento tardio destas plantas teve origem a partir de sementes dormentes que foram sucessivamente completando seu ciclo durante o desenvolvimento do canavial ao longo dos três cortes. Esta ocorrência é frequentemente observada em canaviais comerciais que utilizam-na como adubo verde durante sua reforma, caracterizando assim uma peculiaridade indesejável desta espécie.

A concentração de macronutrientes na matéria seca (MS) das leguminosas é apresentada na tabela 4 onde se chama a atenção para a relativa superioridade dos teores de nitrogênio do feijão-de-porco $(3,80 \%)$ e da 
C. juncea $(3,31 \%)$ enquanto as demais espécies apresentaram em média $2,70 \%$ de $N$.

Tabela 4 - Concentração percentual de macronutrientes na matéria seca das leguminosas.

\begin{tabular}{lcccccc}
\hline Leguminosa & $\mathbf{N}$ & $\mathbf{P}$ & $\mathbf{K}$ & $\mathbf{C a}$ & $\mathbf{M g}$ & $\mathbf{S}$ \\
\hline C. juncea & 3,31 & 0,26 & 1,43 & 0,75 & 0,41 & 0,23 \\
C. spectabilis & 2,70 & 0,21 & 2,25 & 1,50 & 0,37 & 0,18 \\
Guandu & 2,58 & 0,19 & 1,13 & 0,46 & 0,19 & 0,16 \\
Mucuna preta & 2,70 & 0,21 & 1,22 & 0,62 & 0,25 & 0,14 \\
Mucuna anã & 2,70 & 0,17 & 1,05 & 0,70 & 0,23 & 0,14 \\
Lablabe & 2,70 & 0,25 & 1,39 & 0,65 & 0,26 & 0,23 \\
Feijão-de-porco & 3,80 & 0,20 & 1,35 & 1,01 & 0,36 & 0,21 \\
\hline
\end{tabular}

A concentração de potássio na MS da Crotalaria spectabilis diferiu bastante das demais, com $2,25 \%$ de $\mathrm{K}$, enquanto as outras leguminosas apresentaram teores na faixa de 1,0 a 1,4\%. Também o teor de cálcio desta espécie foi comparativamente maior, com $1,5 \%$, duas a três vezes superior ao das outras espécies.

A associação da concentração com a produção de matéria seca propiciou o cálculo da extração de macronutrientes pelas leguminosas, podendo-se observar na tabela 5 que a Crotalaria juncea foi bastante superior às demais espécies de adubos verdes, perdendo apenas para a $C$. spectabilis na extração de cálcio.

Estes dados demonstram a elevada capacidade que apresenta o sistema radicular da $C$. juncea na movimentação de nutrientes das camadas mais profundas do solo para a superfície, aliada talvez, à maior capacidade de fixação simbiótica de nitrogênio por suas raízes. 
Tabela 5 - Extração de macronutrientes pelas leguminosas (em $\mathrm{kg} / \mathrm{ha}$ )

\begin{tabular}{lrrrrrr}
\hline Leguminosa & \multicolumn{1}{c}{ N } & \multicolumn{1}{c}{ P } & K & Ca & Mg & \multicolumn{1}{c}{ S } \\
\hline C. juncea & 235.0 & 18.5 & 101.5 & 53.3 & 29.1 & 16.3 \\
C. spectabilis & 113.4 & 8.8 & 94.5 & 63.0 & 15.5 & 7.6 \\
Guandu & 141.9 & 10.5 & 62.2 & 25.3 & 10.5 & 8.8 \\
Mucuna preta & 81.0 & 6.3 & 36.6 & 18.6 & 7.5 & 4.2 \\
Mucuna anã & 105.3 & 6.6 & 41.0 & 27.3 & 9.0 & 5.5 \\
Lablabe & 94.5 & 8.8 & 48.7 & 22.8 & 9.1 & 8.1 \\
Feijão-de-porco & 190.0 & 10.0 & 67.5 & 50.5 & 18.0 & 10.5 \\
\hline
\end{tabular}

\subsection{Cana-de-açúcar}

\subsubsection{Qualidade da matéria-prima}

Os dados relacionados com a qualidade da matéria prima industrializável, apresentados na tabela 6 , demostram que não houve efeito da adubação verde sobre as características tecnológicas da cana-de-açúcar nos três cortes estudados. Apenas os teores de fibra diferiram estatisticamente entre os tratamentos no primeiro corte, contudo, isto não pode ser atribuído aos tratamentos empregados, uma vez que, associando-se aos demais parâmetros levantados neste mesmo corte, estas diferenças tornam-se inconsistentes.

Os baixos teores de açúcares redutores (AR) demonstram que a colheita foi efetuada quando a cana-de-açúcar encontrava-se no ponto ideal de maturação. AR é o valor percentual que expressa o teor de glucose e frutose do caldo. Durante a maturação, à medida que o teor de sacarose aumenta, os AR decrescem de quase $2 \%$ para menos de $0,5 \%$.

A maturação ideal foi ainda confirmada pelos altos níveis de brix, pureza e pol \% cana, que representa toda sacarose contida no caldo. Salienta-se ainda a elevada concentração de açúcar obtida no terceiro corte, com pol \% cana médio próximo a $17 \%$, um teor considerável para uma variedade de riqueza modesta como a SP70-1143. 
Tabela 6 - Características tecnológicas da cana-de-açúcar nos 3 cortes avaliados (valores percentuais).

\begin{tabular}{|c|c|c|c|c|c|}
\hline Tratamento & Brix & Pureza & Fibra & $A R^{(1)}$ & Pol Cana \\
\hline \multicolumn{6}{|l|}{$1^{\circ}$ corte } \\
\hline $\begin{array}{l}\text { Pousio } \\
\text { C. juncea } \\
\text { C. spectabilis } \\
\text { Guandu } \\
\text { Mucuna preta } \\
\text { Mucuna anã } \\
\text { Lablabe } \\
\text { Feijão-de-porco }\end{array}$ & $\begin{array}{l}19.2 \\
19.8 \\
19.3 \\
19.3 \\
19.6 \\
19.3 \\
20.0 \\
19.3 \\
\end{array}$ & $\begin{array}{l}88.42 \\
90.08 \\
88.45 \\
87.47 \\
89.08 \\
89.20 \\
89.88 \\
88.91 \\
\end{array}$ & $\begin{array}{l}12.78 \\
13.03 \\
12.42 \\
13.08 \\
13.56 \\
11.92 \\
13.72 \\
13.50 \\
\end{array}$ & $\begin{array}{l}0.60 \\
0.50 \\
0.62 \\
0.61 \\
0.56 \\
0.47 \\
0.51 \\
0.67 \\
\end{array}$ & $\begin{array}{l}14.18 \\
14.81 \\
14.33 \\
14.00 \\
14.39 \\
14.60 \\
14.77 \\
14.13 \\
\end{array}$ \\
\hline Prob $>F$ & ns & ns & 0.03 & ns & ns \\
\hline \multicolumn{6}{|l|}{$2^{\circ}$ corte } \\
\hline $\begin{array}{l}\text { Pousio } \\
\text { C. juncea } \\
\text { C. spectabilis } \\
\text { Guandu } \\
\text { Mucuna preta } \\
\text { Mucuna anã } \\
\text { Lablabe } \\
\text { Feijão-de-porco }\end{array}$ & $\begin{array}{l}20.9 \\
20.8 \\
21.3 \\
21.0 \\
21.1 \\
21.1 \\
21.3 \\
21.2\end{array}$ & $\begin{array}{l}90.01 \\
90.14 \\
89.05 \\
90.55 \\
89.36 \\
89.48 \\
90.29 \\
89.93\end{array}$ & $\begin{array}{l}15.73 \\
14.61 \\
13.96 \\
14.14 \\
14.18 \\
14.76 \\
14.60 \\
14.56\end{array}$ & $\begin{array}{l}0.44 \\
0.46 \\
0.45 \\
0.43 \\
0.39 \\
0.37 \\
0.37 \\
0.36\end{array}$ & $\begin{array}{l}14.90 \\
15.15 \\
15.51 \\
15.54 \\
15.34 \\
15.22 \\
15.54 \\
15.42\end{array}$ \\
\hline Prob $>F$ & ns & ns & ns & ns & ns \\
\hline \multicolumn{6}{|l|}{$3^{\circ}$ corte } \\
\hline $\begin{array}{l}\text { Pousio } \\
\text { C. juncea } \\
\text { C. spectabilis } \\
\text { Guandu } \\
\text { Mucuna preta } \\
\text { Mucuna anã } \\
\text { Lablabe } \\
\text { Feijão-de-porco }\end{array}$ & $\begin{array}{l}23.9 \\
23.4 \\
23.4 \\
23.8 \\
23.7 \\
23.6 \\
23.5 \\
23.5 \\
\end{array}$ & $\begin{array}{l}89.50 \\
89.20 \\
89.59 \\
89.19 \\
89.48 \\
89.41 \\
89.34 \\
89.89 \\
\end{array}$ & $\begin{array}{l}14.51 \\
15.04 \\
15.05 \\
14.69 \\
15.37 \\
15.03 \\
15.43 \\
14.95 \\
\end{array}$ & $\begin{array}{l}0.49 \\
0.51 \\
0.52 \\
0.44 \\
0.49 \\
0.51 \\
0.49 \\
0.53 \\
\end{array}$ & $\begin{array}{l}17.32 \\
16.79 \\
16.80 \\
17.12 \\
16.90 \\
16.93 \\
16.73 \\
17.00 \\
\end{array}$ \\
\hline Prob. $>F$ & ns & ns & ns & ns & ns \\
\hline
\end{tabular}

(1) Açúcares redutores 


\subsubsection{Produção Agrícola}

Foi na produção agrícola, avaliada em termos de toneladas de colmos por hectare (TCH) e sua associação com o teor de açúcar, expressa em toneladas de pol por hectare (TPH), que o efeito da adubação verde manifestou-se comparativamente entre espécies e o pousio (Tabela 7).

Tabela 7 - Produtividade agrícola dos 3 cortes obtidos, em toneladas de colmos por hectare (TCH) e toneladas de pol por hectare (TPH).

\begin{tabular}{|c|c|c|c|c|c|c|}
\hline \multirow[t]{2}{*}{ Tratamento } & \multicolumn{2}{|c|}{$1^{\circ}$ corte } & \multicolumn{2}{|c|}{$2^{\circ}$ corte } & \multicolumn{2}{|c|}{$3^{\circ}$ corte } \\
\hline & $\mathrm{TCH}$ & TPH & $\mathrm{TCH}$ & TPH & $\mathrm{TCH}$ & TPH \\
\hline Pousio & $118.5 \mathrm{~b}$ & $16.73 \mathrm{~d}$ & $84.2 \mathrm{~b}$ & $12.55 \mathrm{~b}$ & $64.4 a b$ & $11.16 \mathrm{a}$ \\
\hline C. juncea & $133.1 \mathrm{a}$ & $19.71 \mathrm{a}$ & $90.4 \mathrm{ab}$ & $13.69 \mathrm{ab}$ & $62.7 \mathrm{ab}$ & $10.50 \mathrm{a}$ \\
\hline C. spectabilis & $133.9 \mathrm{a}$ & $19.19 a b$ & $92.3 \mathrm{a}$ & $14.31 \mathrm{a}$ & $66.2 \mathrm{a}$ & $11.09 \mathrm{a}$ \\
\hline Guandu & $126.6 \mathrm{ab}$ & $17.74 \mathrm{bcd}$ & $85.4 a b$ & $13.28 a b$ & $61.2 \mathrm{ab}$ & $10.50 \mathrm{a}$ \\
\hline Mucuna preta & $119.7 \mathrm{~b}$ & $17.22 \mathrm{~cd}$ & $88.1 \mathrm{ab}$ & $13.50 \mathrm{ab}$ & $59.6 a b$ & $10.08 a$ \\
\hline Mucuna anã & $126.0 \mathrm{ab}$ & $18.39 \mathrm{abc}$ & $87.8 \mathrm{ab}$ & $13.38 a b$ & $58.4 \quad b$ & $9.92 a$ \\
\hline Lablabe & $126.7 a b$ & $18.72 a b$ & $85.7 \mathrm{ab}$ & $13.32 \mathrm{ab}$ & $60.0 \mathrm{ab}$ & $10.05 a$ \\
\hline Feijão-de-porco & $126.2 \mathrm{ab}$ & $17.84 \mathrm{bcd}$ & $84.5 \mathrm{ab}$ & $13.03 \mathrm{ab}$ & $60.1 \mathrm{ab}$ & $10.22 \mathrm{a}$ \\
\hline dms Duncan $5 \%$ & $9.49^{\star *}$ & $1.46^{\star \star}$ & $7.82 \mathrm{~ns}$ & $1.47 \mathrm{~ns}$ & $7.41 \mathrm{~ns}$ & $1.34 \mathrm{~ns}$ \\
\hline
\end{tabular}

Médias seguidas da mesma letra não diferem estatisticamente pelo teste de Duncan, ao nivel de $5 \%$ de probabilidade.

No primeiro corte houve diferença estatisticamente significativa entre tratamentos, tendo as crotalárias ( $C$. juncea e $C$. spectabilis) obtido as melhores produções, com 133,1 e 133,9t/ha de colmos, respectivamente; cerca de $15 \mathrm{t}$ de diferença em relação aos piores tratamentos que foram o pousio $(118,5 \mathrm{t} / \mathrm{ha})$ e mucuna preta $(119,7 \mathrm{t} / \mathrm{ha})$, confirmando que a baixa produtividade da mucuna preta refletiu na ausência de efeito benéfico para a cana-de-açúcar cultivada em seguida. Em escala intermediária posicionaram-se o guandu, a mucuna anã, o lablabe e o feijão-de-porco, com produtividades próximas a 126tha de colmos. Como os teores de açúcar não diferiram entre si, a avaliação dos dados de TPH concordam com os de TCH. 
No segundo corte, a análise de variação dos dados não mostrou diferença significativa entre os tratamentos empregados, contudo, as médias obtidas neste corte mantém coerência com as produtividades do primeiro corte, havendo uma tendência de maior produção para as crotalárias, obtendo em relação a área em pousio 6,2 t/ha de colmos a mais para a $C$. juncea e 8,1 t/ha para a $C$. spectabilis, sendo neste caso apontada diferença pelo teste de Duncan a $5 \%$ de probabilidade. Também na avaliação do TPH do segundo corte, apenas foi apontada diferença entre o pousio $(12,55 t /$ ha $)$ e $C$. spectabilis $(14,31$ t/ha).

Para o terceiro corte as diferenças foram ainda mais reduzidas, sem guardar completa relação com as produtividades obtidas nos dois primeiros cortes.

Correlacionado-se as médias de produção de matéria seca das leguminosas com a produtividade agrícola dos três cortes do canavial, isoladamente em cada corte e na somatória obtida nestes tratamentos, observou-se que houve correlação linear estatisticamente significativa apenas entre os dados relativos ao primeiro corte, tanto para TCH como para TPH, mostrando mais uma vez que o efeito da adubação verde manifestou-se mais pronunciadamente no primeiro corte, e que este esteve intimamente ligado à produção de matéria seca do adubo verde cultivado em rotação (Tabela 8 e Figura 2).

Observa-se que, à medida que evoluem os cortes, caem os coeficientes de determinação $\left(r^{2}\right)$ obtidos pelas regressões lineares entre MS e TCH ou TPH, demonstrando que o fenômeno deixa de ser explicado por esta relação.

Investigando-se a contribuição isolada das quantidades acumuladas, ou extraídas, de cada macronutriente pela matéria seca das leguminosas, no reflexo da produção do canavial cultivado subsequentemente constatou-se que, apenas as quantidades extraídas de potássio e cálcio guardaram alguma relação com a produção da cana-de-açúcar. A extração de potássio correlacionou-se com TCH e TPH do primeiro corte e do ciclo (soma dos três cortes), e a extração de cálcio correlacionou-se com TCH do primeiro corte e TPH do primeiro corte e do ciclo (Tabela 9 e Figuras 3 e 4). 
Estranhou-se o fato de não ter havido relação da produção de cana com a extração de nitrogênio, uma vez que este fato diferenciaria a capacidade das leguminosas testadas no aspecto da fixação simbiótica do elemento, o que não ocorreu.

Tabela 8 - Correlação linear entre produção de matéria seca das leguminosas (t/ha) em rotação e produção agrícola (TCH e TPH) subsequente de 3 cortes de cana-de-açúcar.

\begin{tabular}{cccc}
\hline Relação & Equação & $\mathbf{r}^{2}$ & Prob $>\mathbf{f}$ \\
\hline MS $\times$ tch $1^{\circ}$ corte & $y=118,25+2,009 \times$ & 0,58 & 0,03 \\
MS $\times$ tch $2^{\circ}$ corte & $y=84,99+2,128 \times$ & 0,17 & $n s$ \\
MS $\times$ tch $3^{\circ}$ corte & $y=62,36-2,109 \times$ & 0,02 & $n s$ \\
MS $\times$ tch do ciclo & $y=265,61+2,377 \times$ & 0,29 & $n s$ \\
MS $\times$ tph $1^{\circ}$ corte & $y=16,78+0,346 \times$ & 0,50 & 0,05 \\
MS $\times$ tph $2^{\circ}$ corte & $y=12,89+0,123 \times$ & 0,26 & $n s$ \\
MS $\times$ tph $3^{\circ}$ corte & $y=10,74-0,075 x$ & 0,10 & $n s$ \\
MS $\times$ tph do ciclo & $y=40,37+0,409 x$ & 0,33 & $n s$ \\
\hline
\end{tabular}

Tabela 9 - Correlação linear entre extração de $\mathrm{K}$ e $\mathrm{Ca}(\mathrm{kg} / \mathrm{ha})$ pelas leguminosas e produção de cana-de-açúcar (TCH e TPH) cultivada subsequentemente.

\begin{tabular}{cccc}
\hline Relação & Equação & $\mathbf{r}^{2}$ & Prob > f \\
\hline $\mathrm{K} \times$ tch $1^{\circ}$ corte & $y=116,38+0,1716 \times$ & 0,82 & 0,01 \\
$\mathrm{~K} \times$ tph $1^{\circ}$ corte & $y=16,70+0,0260 \times$ & 0,56 & 0,05 \\
$\mathrm{~K} \times$ tch do ciclo & $y=225,54-0,3219 \times$ & 0,79 & 0,01 \\
$\mathrm{~K} \times$ tph do ciclo & $y=39,14+0,0480 \times$ & 0,71 & 0,01 \\
Ca $x$ tch $1^{\circ}$ corte & $y=119,20+0,222 \times$ & 0,67 & 0,02 \\
Ca $x$ tch do ciclo & $y=260,61+0,422 \times$ & 0,66 & 0,03 \\
Ca $x$ tph do ciclo & $y=39,97+0,061 \times$ & 0,56 & 0,05 \\
\hline
\end{tabular}



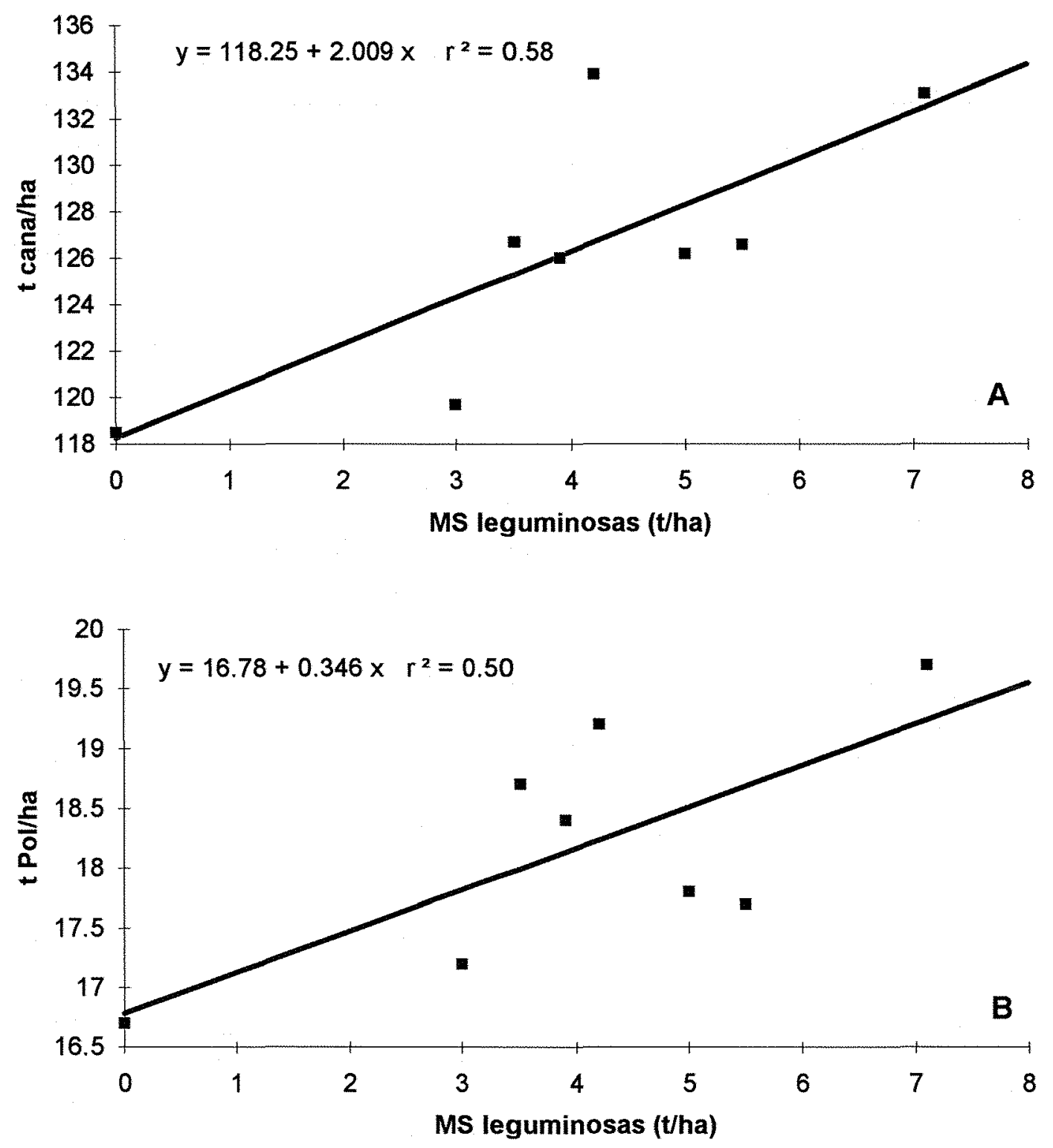

Figura 2 - Relação entre produção de matéria seca dos adubos verdes e produtividade da cana-de-açúcar no primeiro corte (t cana/ha em A e t Pol/ha em B). 

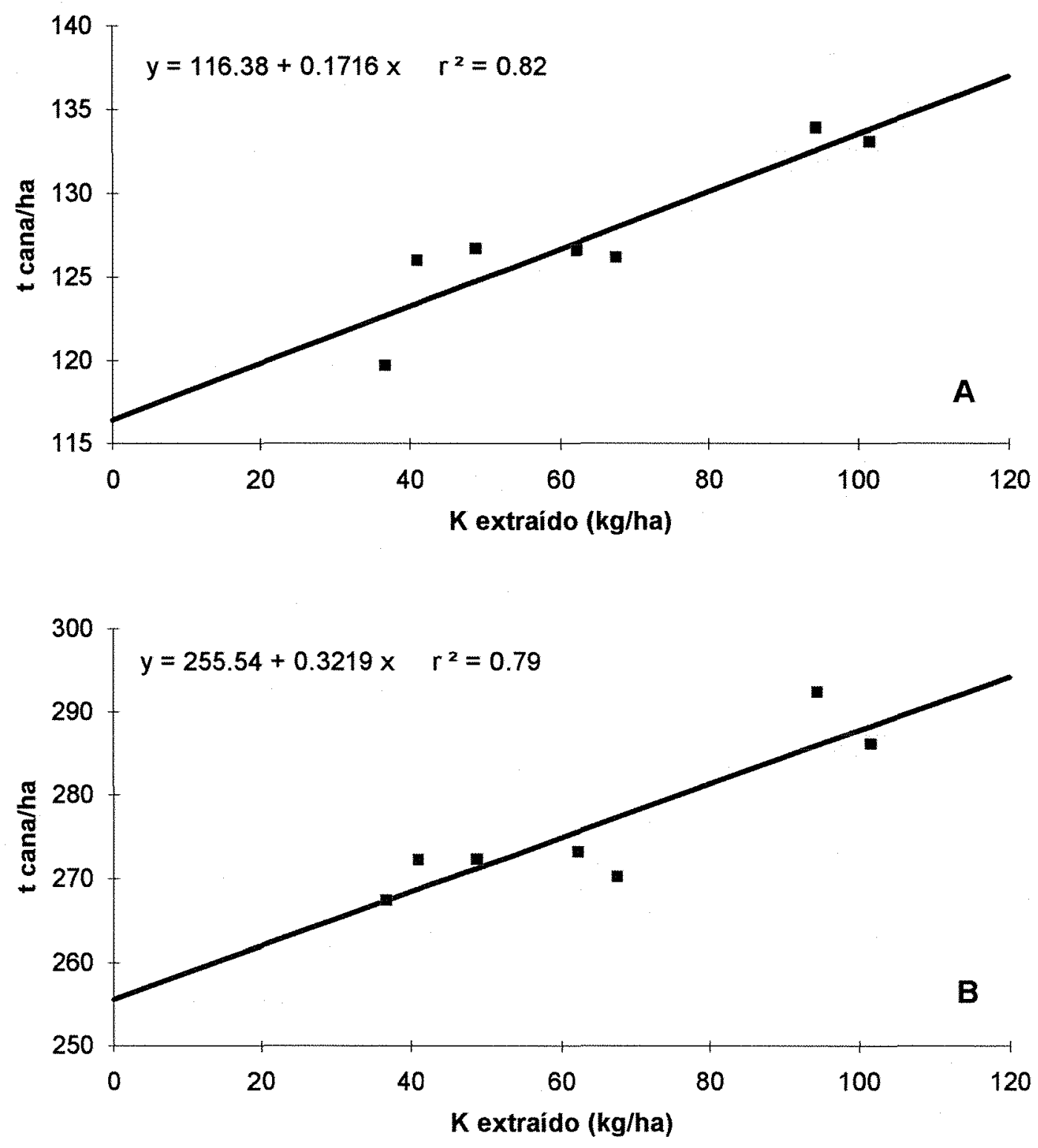

Figura 3 - Relação entre extração de potássio pela matéria seca dos adubos verdes e produtividade da cana-de-açúcar (t cana/ha) cultivada subsequentemente, no primeiro corte (A) e na soma dos 3 cortes (B). 

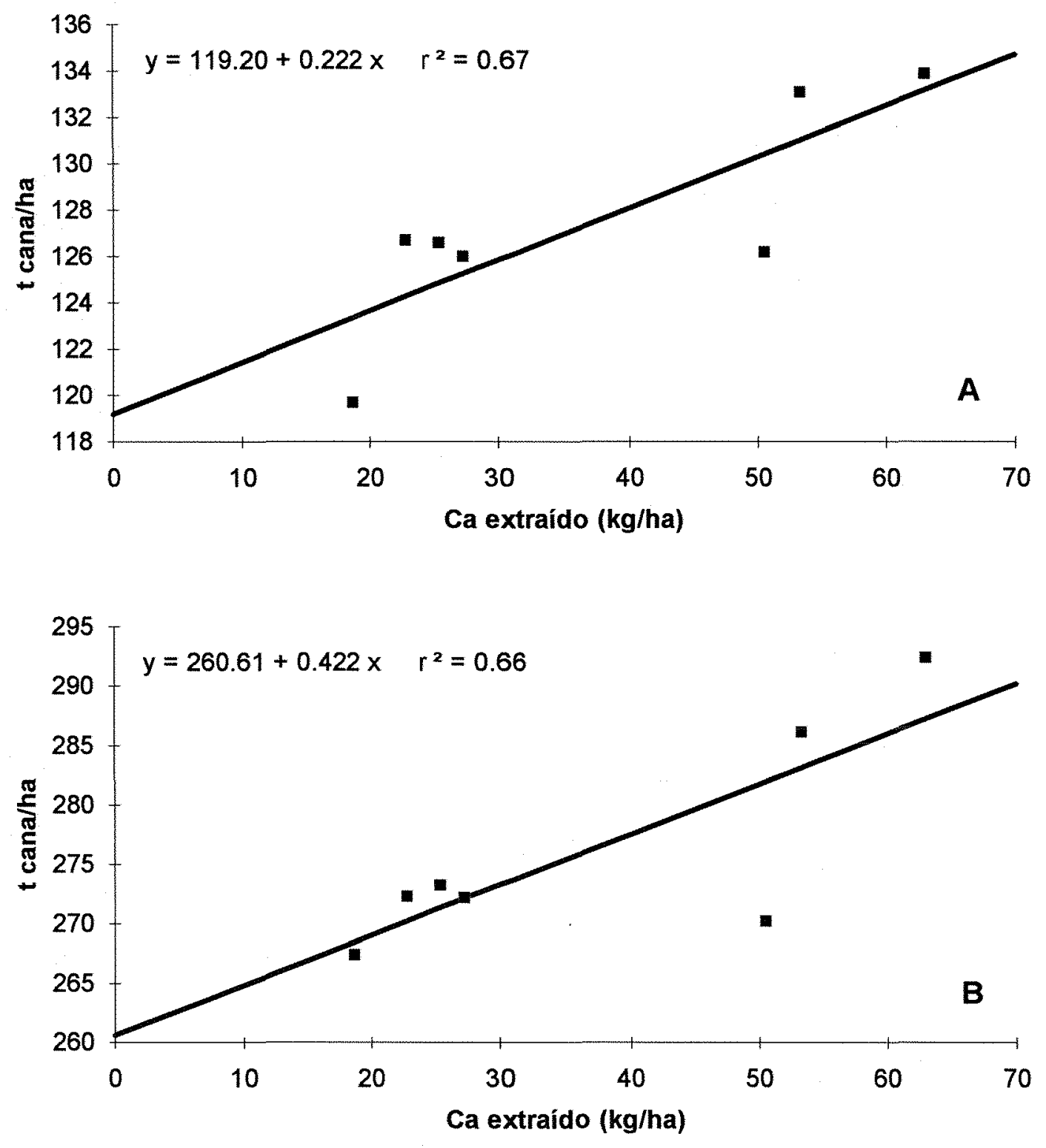

Figura 4 - Relação entre extração de cálcio pela matéria seca dos adubos verdes e produtividade da cana-de-açúcar (t cana/ha) cultivada subsequentemente, no primeiro corte (A) e na soma dos 3 cortes (B). 


\subsection{Atributos químicos do solo}

Quando são observadas alterações nos atributos químicos do solo devido ao emprego de leguminosas como adubos verdes, normalmente estes são revertidos em pouco tempo às condições iniciais, perdurando este efeito por poucos meses, quando ocorrem (WUTKE, 1968; BULISANI et al., 1972; ANDRADE, 1982; WESTCOTT \& MIKKELSEN; 1987).

Os resultados obtidos neste experimento concordam com os destes autores, conforme observa-se na tabela 10 , onde não se constata nenhuma alteração expressiva no $\mathrm{pH}$, teor de nutrientes, matéria orgânica, alumínio, capacidade de troca catiônica, saturação por bases e saturação por alumínio do solo; nem mesmo na análise efetuada logo após a incorporação das leguminosas por ocasião do plantio da cana, não sendo possível, portanto, atribuir o maior rendimento da cultura nos primeiros cortes de alguns tratamentos, às modificações de ordem química que as leguminosas, cultivadas e incorporadas como adubos verdes, teriam proporcionado ao solo. 
Tabela 10 - Resultados analíticos do solo $(0-25 \mathrm{~cm})$ antes e após o plantio das leguminosas e antes de cada corte da cana-de-açúcar da área experimental.

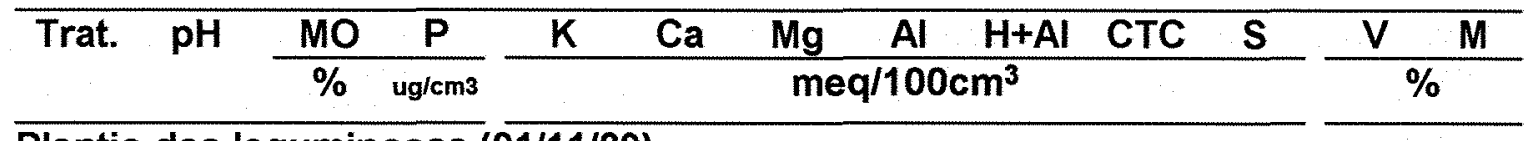

Plantio das leguminosas $(01 / 11 / 89)$

\begin{tabular}{llllllllllll}
4.4 & 1.44 & 8 & 0.11 & 0.46 & 0.34 & 0.63 & 3.50 & 4.41 & 0.9 & 21 & 41 \\
\hline
\end{tabular}

Plantio da cana-de-açúcar (09/03/90)

\begin{tabular}{lllllllllllll}
1 & 4.6 & 1.25 & 8 & 0.05 & 0.54 & 0.39 & 0.33 & 3.20 & 4.18 & 1.0 & 23 & 25 \\
2 & 4.5 & 1.21 & 7 & 0.07 & 0.57 & 0.43 & 0.38 & 3.10 & 4.17 & 1.1 & 26 & 26 \\
3 & 4.5 & 1.28 & 7 & 0.08 & 0.49 & 0.38 & 0.37 & 3.20 & 4.15 & 1.0 & 23 & 28 \\
4 & 4.6 & 1.18 & 6 & 0.08 & 0.52 & 0.42 & 0.31 & 3.10 & 4.12 & 1.0 & 25 & 23 \\
5 & 4.7 & 1.18 & 7 & 0.11 & 0.60 & 0.49 & 0.23 & 2.90 & 4.10 & 1.2 & 29 & 16 \\
6 & 5.0 & 1.21 & 7 & 0.10 & 0.75 & 0.66 & 0.14 & 2.60 & 4.11 & 1.5 & 37 & 8 \\
7 & 4.7 & 1.25 & 7 & 0.11 & 0.64 & 0.51 & 0.23 & 2.80 & 4.06 & 1.3 & 31 & 15 \\
8 & 4.6 & 1.28 & 7 & 0.10 & 0.62 & 0.46 & 0.28 & 3.20 & 4.38 & 1.2 & 27 & 19 \\
\hline
\end{tabular}

Após primeiro corte (07/08/91)

\begin{tabular}{lllllllllllll}
1 & 4.5 & 1.60 & 5 & 0.03 & 0.63 & 0.49 & 0.44 & 3.10 & 4.25 & 1.2 & 27 & 28 \\
2 & 4.4 & 1.72 & 7 & 0.04 & 0.63 & 0.46 & 0.48 & 3.20 & 4.33 & 1.1 & 26 & 30 \\
3 & 4.5 & 1.66 & 5 & 0.04 & 0.57 & 0.44 & 0.45 & 3.10 & 4.15 & 1.1 & 25 & 30 \\
4 & 4.3 & 1.53 & 7 & 0.04 & 0.53 & 0.42 & 0.53 & 3.40 & 4.39 & 1.0 & 23 & 35 \\
5 & 4.6 & 1.60 & 5 & 0.04 & 0.67 & 0.51 & 0.38 & 3.00 & 4.22 & 1.2 & 29 & 24 \\
6 & 4.4 & 1.63 & 7 & 0.04 & 0.53 & 0.40 & 0.53 & 3.40 & 4.37 & 1.0 & 22 & 35 \\
7 & 4.5 & 1.69 & 5 & 0.04 & 0.70 & 0.53 & 0.35 & 3.10 & 4.37 & 1.3 & 29 & 22 \\
8 & 4.4 & 1.63 & 7 & 0.04 & 0.53 & 0.36 & 0.56 & 3.40 & 4.33 & 0.9 & 21 & 38 \\
\hline
\end{tabular}

Após segundo corte (07/08/92)

\begin{tabular}{ccccccccccccc}
1 & 4.6 & 1.60 & 10 & 0.09 & 0.50 & 0.40 & 0.50 & 3.70 & 4.69 & 1.0 & 21 & 34 \\
2 & 4.5 & 1.60 & 7 & 0.07 & 0.70 & 0.40 & 0.50 & 3.60 & 4.77 & 1.2 & 25 & 30 \\
3 & 4.5 & 1.50 & 9 & 0.07 & 0.80 & 0.50 & 0.40 & 3.70 & 5.07 & 1.4 & 27 & 23 \\
4 & 4.7 & 1.60 & 6 & 0.06 & 0.60 & 0.40 & 0.40 & 3.60 & 4.66 & 1.1 & 23 & 27 \\
5 & 4.8 & 1.30 & 9 & 0.07 & 1.10 & 0.80 & 0.30 & 3.00 & 4.97 & 2.0 & 40 & 13 \\
6 & 4.5 & 1.60 & 8 & 0.10 & 1.10 & 0.50 & 0.60 & 3.60 & 5.30 & 1.7 & 32 & 26 \\
7 & 4.4 & 1.50 & 10 & 0.13 & 0.50 & 0.30 & 0.60 & 3.60 & 4.53 & 0.9 & 21 & 39 \\
8 & 4.5 & 1.40 & 8 & 0.08 & 1.20 & 0.40 & 0.40 & 3.80 & 5.48 & 1.7 & 31 & 19 \\
\hline
\end{tabular}




\section{CONCLUSÕES}

Das leguminosas testadas como adubos verdes, a mais produtiva foi a Crotalaria juncea, com 7,1 tha de MS, sendo seguida pelo guandu, feijão-de-porco, C. spectabilis, mucuna anã, lablabe e finalmente mucuna preta, que teve problemas de germinação. A C. juncea foi também comparativamente a espécie que mais extraiu macronutrientes.

A adubação verde teve efeito significativo sobre a produtividade da cana-de-açúcar cultivada na sequência, apenas no primeiro corte, sendo a Crotalaria juncea e a Crotalaria spectabilis os melhores adubos verdes para esta cultura cultivada em solo de baixa fertilidade. No segundo corte do canavial as diferenças entre tratamentos, apesar de não significativas estatisticamente, foram inferiores e coerentes com as do primeiro corte. A adubação verde não mostrou efeito sobre a produtividade dos tratamentos no terceiro corte.

Não houve efeito da adubação verde na qualidade tecnológica (teor de açúcar, pureza e fibra) da cana-de-açúcar em nenhum dos 3 cortes avaliados, nem nos atributos químicos do solo onde as leguminosas foram cultivadas. 


\section{REFERÊNCIAS BIBLIOGRÁFICAS}

ABBOUD, A.C.S. \& DUQUE, F.F. Efeitos de materiais orgânicos e vermiculita sobre a sequência feijão-milho-feijão. Pesquisa Agropecuária Brasileira, Brasilia, 21(3):227-36, 1986.

AGUIAR, A.A.L. de. Manual de adubos verdes; um novo conceito em sementes de adubos verdes. Piracicaba, Cia. Industrial de Papel Pirahy, s.d. 12p.

ANDRADE, L.A.B. Efeitos da incorporação de Crotalaria juncea L. sobre algumas características do solo e do desenvolvimento inicial da cana-deaçúcar (Saccharum spp). Piracicaba, 1982. 129p. (Mestrado - Escola Superior de Agricultura "Luiz de Queiroz"/USP).

ARMY, T.J. \& HIDE, J.C. Effects of green manure crops on dryland wheat production in the great plains area of Montana. Agronomy Journal, Madison, 51(4):196-8, 1959.

BADANUR, V.P.; POLESHI, C.M.; NALK, B.K. Effect of organic matter on crop yield and physical and chemical properties of a Vertisol. Journal of the Indian Society of Soil Science, New Delhi, 38(3):426-9, 1990. Apud Soils and Fertilizers, Wallingford, $54(7): 1082,1991$. (Resumo).

BELLINGIERI, P.A.; KANESIRO, M.A.B.; DURIGAN,J.F.; HERNANDEZ, F.B T.; MALHEIROS, E.B. Utilização de adubos verdes no aumento da produção de alimentos. I. Efeito da adubação verde na produtividade e conteúdo protéico do milho. Científica, Jaboticabal, 17(1):25-33, 1989. 
BONFILS, P. Évolution de la matière organique dans deux sols du Sénégal. Agronomie Tropicale, Paris, 18(12):1254-79, 1963.

BULISANI, E.A.; MIYASAKA, S.; ALMEIDA, L.D.; SCARANARI, H.J.; PINTO, H.S. Estudos ecológicos com o feijoeiro (Phaseolus vulgaris L.). I. Efeitos da incorporação de massa vegetal ao solo, e do sombreamento parcial. Bragantia, Campinas, 31(7):83-95, jan.1972.

CAMPOS, J.C.B. Uso de leguminosas para adubação verde da cana-deaçúcar. Fundenor Pesquisa. InformaçãoTécnica, Campos, 2, fev. 1977. 4p.

CARDOSO, E.M. Contribuição para o estudo da adubação verde dos canaviais. Piracicaba, 1956. 109p. (Doutorado - Escola Superior de Agricultura "Luiz de Queiroz"/USP).

COOPERATIVA CENTRAL DOS PRODUTORES DE AÇÚCAR E ÁLCOOL DO ESTADO DE SÄO PAULO. Amostragem e análise da cana-de-açúcar. Centro de Tecnologia Copersucar, Divisão Agronômica, 1980. 37p.

COOPERATIVA CENTRAL DOS PRODUTORES DE AÇÚCAR E ÁLCOOL DO ESTADO DE SÃO PAULO. Novas variedades Copersucar. Boletim Técnico. Copersucar, São Paulo, (Ed.Especial) :18-21, mar. 1983.

COPE, J.T.; STURKIE, D.G.; HILTBOLD, A.E. Effects of manure, vetch, and commercial nitrogen on crop yields and carbon and nitrogen contents of a fine sandy loam over a 30-year period. Soil Science Society of America Proceedings, Madison, 22(6):524-7, 1958.

CORDEIRO, D.S.; KICHEL, A.N.; PAULETTO, A.E.; ASSIS, V.G.; SILVEIRA Jr., P. Peso da matéria seca de diversas culturas de verão utilizadas como adubação verde na encosta do sudeste do Rio Grande do Sul. Resultados de pesquisa de soja 1980-81. Pelotas, UEPAE de Pelotas, 1983a. Apud Field Crop Abstracts, Wallingford, 38(3):126, 1985. (Resumo). 
CORDEIRO, D.S.; KICHEL, A.N.; TURATTI, A.L.; ASSIS, V.G.; SILVEIRA Jr., P. Efeito da adubação mineral no resíduo de culturas de verão utilizadas como adubação verde no rendimento de grãos de soja. Resultados de pesquisa de soja 1981/82. Pelotas, UEPAE de Pelotas, 1983b. Apud Field Crop Abstracts, Wallingford, 37(12):983-4, 1985. (Resumo).

CURI, S.M. \& SILVEIRA, S.G.P. Controle do nematóide Meloydogine incognita, parasito da soja, em condições de campo. In: REUNIÃO BRASILEIRA DE NEMATOLOGIA, 3., Mossoró, 1978. Resumos. Mossoró, Escola Superior de Agricultura de Mossoró, Coleção Mossoroense LXII, 1978. p. 106-7.

CURI, S.M.; SILVEIRA, S.G.P.; FERREIRA, S.; PASSOS, S.M.G.; CRUZ, V.R Controle de nematóide reniforme, Rotylenchulus reniforme, na cultura do algodoeiro. In: REUNIÃO DA SOCIEDADE BRASILEIRA DE NEMATOLOGIA, 4., São Paulo, 1979, Resumos. São Paulo, Sociedade Brasileira de Nematologia, 1979. p. 41.

DE-POLLI, H. \& CHADA, S.S. Adubação verde incorporada ou em cobertura na produção de milho em solo de baixo potencial de produtividade. Revista Brasileira de Ciência do Solo, Campinas, 13(3):287-93, 1989.

DUTRA, G.R.P. Adubos verdes; sua produção e modo de emprego. São Paulo, Secretaria da Agricultura, 1919. 76p.

GAUDÊNCIO, C.A.; YORINORI, J.T.; JASTER, F.; WOBETO, C.; TORRES, E.; HOMECHIN, M.; CORSO, I.C.; MACHADO, C.C. Rotação girassol-milhosoja, sucedida por culturas de inverno, adubação verde e pousio. Documentos. Centro Nacional de Pesquisa de Soja, Londrina, 36:256-67, 1988.

GLÓRIA, N.A. da; MATTIAZZO, M.E.; PEREIRA, V.; PARO, J.M. Avaliação da produção de adubos verdes. Saccharum, São Paulo, $\underline{3}(8): 31-5,1980$. 
GONÇALVES, N.H. Efeitos de épocas de incorporacão de labe-labe ao solo sobre a sucesSão girassol (Helianthus annuus L.)-amendoim (Arachis hypogaea L.). Jaboticabal, 1985. 64p (Graduação - Faculdade de Ciências Agrárias e Veterinárias de Jaboticabal/UNESP).

HILL, J.N.S. Consideration of the sugarcane stubble replacement decision at

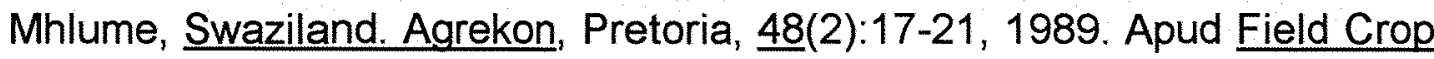
Abstracts, Wallingford, 44(3):231, 1991. (Resumo).

HUANG, B. Studies on effect of turnover of green-manure and wheat straw into soil on soil fertility. I. Effect of green-manure and wheat straw on characteristics of aggregates and organic matter in soil. Acta Pedologica Sinica, Beijing, 21(2):113-22, 1984. Apud Soils and Fertilizers, Wallingford, $\underline{48}(1): 28,1985$. (Resumo).

HUSSAIN, A.; HUSSAIN, A.; CHUGHTAI, F.A.; BUTT, M.B. Effect of leucaena and sesbania leaf manuring on crop growth and physico-chemical properties of soil. Nitrogen Fixing Tree Research Reports, Bangkok, $\underline{5}: 6-7$, 1987. Apud Field Crop Abstracts, Wallingford, 43(10):907, 1990. (Resumo).

JAYABAL, $V_{\text {;; }}$ PANNEERSELVAM, R.; CHOCKALINGAM, $S$. Effect of incorporation of legumes on yield and quality of sugarcane. Bharatyia Sugar, New Delhi, 15(2):29-30, 1989. Apud Field Crop Abstracts, Wallingford, $44(10): 980,1991$. (Resumo).

KAGE, H. Adubação verde; as observações de um lavrador. In: MIYASAKA, S.; CAMARGO, O.A.; CAVALERI, P.A.; GODOY, I. J.; WERNER, J.C.; CURI, S.M.; LOMBARDI NETO, F.; MEDINA, J.C.; CERVELLINI, G.S.; BULISANI, E.A. Adubação orgânica, adubação verde e rotação de culturas no Estado de São Paulo. 2.ed. Campinas, Fundação Cargill, 1984. pt.2, p. 113-38.

KIEHL, E.J. Consorciação de leguminosas. 1. Nova disposição de linhas de plantas suporte. In: CONGRESSO BRASILEIRO DE CIÊNCIA DO SOLO, 7., Piracicaba, 1959. Resumos. Piracicaba, SBCS, 1959. p. 35. 
KIEHL, E.J. Contribuição para o estudo da poda e da decomposição de adubos verdes. Piracicaba, 1960. 113p. (Livre-docência - Escola Superior de Agricultura "Luiz de Queiroz"/USP).

LI, S.L. A preliminary study on rational fertilization in high yielding sugarcane areas. Journal of Fugian Agricultural College, Fugian, 12(2):165-76, 1983. Apud Horticultural Abstracts, Wallingford, 55(2):165, 1985. (Resumo).

MACEDO, N. \& BOTELHO, P.S.M. Legumes in rotation with sugarcane and termite control. In: INTERNATIONAL SOCIETY OF SUGAR CANE TECHNOLOGISTS CONGRESS, 22., Cartagena, 1995. Proceedings. (No prelo)

MACRAE, R.J. \& MEHUYS, G.R. Effects of green manuring in rotation with corn on the physical properties of two Quebec soils. Biological Agriculture and Horticulture, Berkhamsted, 4(4):257-70, 1987. Apud Soils and Fertilizers, Wallingford, 50(11):1345, 1987. (Resumo).

MAGALHÃES, J.C.A.J.; VIEIRA, R.F.; PEREIRA, J.; PERES, J.R.R. Efeito da adubação verde na disponibilidade de fósforo de fosfatos, numa sucessão de culturas, em solo de cerrado. Revista Brasileira de Ciência do Solo, Campinas, 15(3):329-37, 1991.

MANHÃES, M. S. \& CRUZ FILHO, D.J. Avaliação dos rendimentos de leguminosas para adubação verde na zona canavieira do Estado de São Paulo. Saccharum, São Paulo, $\underline{6}(25): 40-4,1983$.

MIYASAKA, S.; CAMARGO, P.; INFORZATO, R.; IGUE, T. Efeitos da cobertura e da incorporação ao solo, imediatamente antes do plantio, de diferentes formas de matéria orgânica não decomposta, na cultura do feijoeiro. Bragantia, Campinas, 25(32):349-63, 1966a. 
MIYASAKA, S.; FREIRE, E.S.; MASCARENHAS, H.A.A.; NERY, C.; CAMPANA, M.; SORDI, G. de. Efeito da adubação verde com uma gramínea e quatro leguminosas sobre a produção do feijoeiro "da seca", em terra roxa misturada. Bragantia, Campinas, 25(25):277-89, out. 1966b.

MIYASAKA, S.; CAMARGO, O.A.; CAVALERI, P.A.; GODOY, I.J.; WERNER, J.C.; CURI, S.M.; LOMBARDI NETO, F.; MEDINA, J.C.; CERVELLINI, G.S.; BULISANI, E.A. Adubação orgânica, adubação verde e rotação de culturas no Estado de São Paulo. 2.ed. Campinas, Fundação Cargill, 1984. 138p.

MUZZILI, O. A adubação verde como alternativa para a melhoria da fertilidade do solo e racionalização do uso de fertilizantes. Informe da Pesquisa. IAPAR. Londrina, 10(68):1-14, jul. 1986.

MUZZILI, O.; OLIVEIRA, E.L.; GERAGE, A.C.; TORNERO, M.T. Adubação nitrogenada em milho no Paraná. III. Influência da recuperação do solo com adubação verde de inverno nas respostas à adubação nitrogenada. Pesquisa Agropecuária Brasileira, Brasília, 18(1):23-7, jan. 1983.

NOGUEIRA, F.D.; GUIMARÃES, P.T.G.; PAULA, M.B.; FARIA, J.F. Gesso, fosfato natural e adubo verde na cultura do alho em solo aluvial. Revista Brasileira de Ciência do Solo, Campinas, 13(3):349-54, 1989.

NOVARETTI, W.R.T.; ERSENI, J.N.; WENIG Fo, G. Resultados preliminares do uso de Crotalaria spectabilis no controle de nematóides em cana-deaçúcar. Sociedade Brasileira de Nematologia, s.I.,2: 159-63, 1977.

OLSEN, F.J. \& JONES, J.H. Organic amendments compared to topsoil replacement for prime farmland reclamation. Landscape and Urban Planning, Amsterdam, 17(2):197-203, 1989. Apud Soils and Fertilizers, Wallingford, $\underline{53}(2): 224,1990$. (Resumo). 
PANDIT, S.N. \& JAFRI, S.M.H. Effect of green manuring on micronutrient status of plant and soils under monoculture of sugarcane. Indian Journal of Agriculture Sciences, New Delhi, 56(12):884-8, 1986. Apud Soils and Fertilizers, Wallingford, 50(7):852, 1987. (Resumo).

PIAMONTE, R. Contribuição ao desenvolvimento de novos métodos para adubação verde. Boletím do Instituto Biodinâmico, Botucatu, 11(67):3-6, mar. 1992.

PIETERS, A. J. Green manuring; principles and practice. New York, John Wiley, 1927. 356p.

RACHHPAL-SING; VIG, A.C.; SINGH, N.S.; SHING, R. Nitrogen substitution with green-manures in maize-wheat rotation. Indian Jounal of Agronomy, New Delhi, 27(4):371-5, 1982. Apud Soils and Fertilizers, Wallingford, 47(7):831, 1984. (Resumo).

RAIJ, B. van; QUAGGIO, J.A.; CANTARELLA, H.; FERREIRA, M.E.; LOPES, A.S.; BATAGLIA, O.C. Análise química do solo para fins de fertilidade. Campinas, Fundação Cargill, 1987. 170p.

RAMUNNI, A.; SCIALDONE, R.; PIGNALOSA, V. Agronomic properties of a volcanic ash-derived soil as affected by uncomposted organic materials. Plant and Soil, The Hague, 102(2):247-51, 1987. Apud Soils and Fertilizers, Wallingford, 51(3):229, 1988. (Resumo).

RESCK, D.V.S.; SHARMA, R.D.; PEREIRA, J. Efeito de quinze espécies de adubos verdes, na capacidade de retenção de água e no controle de nematóides, em latossolo vermelho escuro sob cerrado. Pesquisa Agropecuária Brasileira, Brasília, 17(3):459-67, mar. 1982. 
RIBEIRO, P.G.F. Influência do estádio fenológico da Crotalaria juncea L. e da Mucuna aterrima (Piper e Tracy) Holland. sobre a decomposição da fitomassa e seu efeito fertilizante. Piracicaba, 1991. 131p. (MestradoEscola Superior de Agricultura "Luiz de Queiroz"/USP).

SARAVANAN, A.; VELU, V.; RAMANATHAN, K.M. Effect of combined application of bio, organic and chemical fertilizers on physico-chemical properties, nitrogen trasformation and yield of rice in submerged soils of Cauvery delta. Oryza, Cuttack, 24(1):1-6, 1987. Apud Soils and Fertilizers, Wallingford, 51(3):249-50, 1988. (Resumo).

SHAAFFHAUSEN, R.V. Recuperação econômica de solos em regimes tropicais através de leguminosas e microelementos. In: CONGRESSO LATINO-AMERICANO DE BIOLOGIA DO SOLO, 2., Santa Maria, 1968. Anais. 1968. p. 1-12.

SILVA, E.M.R.; ALMEIDA, D.L.; FRANCO, A.A; DöBEREINER, J. Adubação verde no aproveitamento de fosfato em solo ácido. Revista Brasileira de Ciência do Solo, Campinas, $\underline{9}(1): 85-8,1985$.

SILVA, J.A.A. da. Efeitos do cultivo intercalar de adubos verdes na formação de pomares de citros. Jaboticabal, 1992. 97p. (Graduação - Faculdade de Ciências Agrárias e Veterinárias de Jaboticabal/UNESP)

TANAKA, R.T.; SANTOS, P.R.R.S.; FREIRE, F.M. Efeito da adubação verde no teor de matéria orgânica do solo e na produção de dois cultivares de soja (Glycine max (L.) Merr.). In: CONGRESSO BRASILEIRO DE CIÊNCIA DO SOLO, 18., Salvador, 1981. Resumos. Salvador, SBCS, 1981. p. 98-9.

VITTI, G.C.; FERREIRA, M.E.; PERECIN, D.; ZANETTI NETO, P. Influência de cinco leguminosas, como adubação verde, na fertilidade de um latossolo vermelho amarelo fase arenosa (LVa). Científica, Jaboticabal, $\underline{7}(3): 431-5$, 1979. 
VITTI, G.C.; DONADIO, L.C.; SILVA, J.A.A.; CABRITA, J.R.M.; SEMPIONATO, J.O.; NAKAYAMA, L.I. Avaliação de adubos verdes plantados intercalar à cultura de citros. I. Primeiro plantio. In: REUNIÃO BRASILEIRA DE FERTILIDADE DE SOLO E NUTRIÇÃO DE PLANTAS, 20., Piracicaba, 1992. Anais. Piracicaba, SBCS, 1992. p. 332-3.

WESTCOTT, M. P. \& MIKKELSEN, D. S. Effect of green manure on rice soil fertility in the United States. In: SYMPOSIUM ON SUSTEINABLE AGRICULTURE, Manila, 1987. Green manure in rice farming. Manila, IRRI, 1978. p. $257-74$.

WUTKE, A.C.P. \& ALVAREZ, R. Restauração do solo para a cultura de canade-açúcar. III. Período 1958-61 e condições gerais. Bragantia, Campinas,

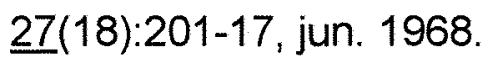

YADOV, R.L.; KISHAN-SINGH; SINGH, K. Long term experiments with sugarcane under intensive cropping systems and variation in soil fertility. Indian Journal of Agronomy, New Delhi, 31(4):322-5, 1986. Apud Field Crop Abstracts, Wallingford, 41(4):333, 1988. (Resumo).

YATES, F. Análise de uma experiência de rotação. Bragantia, Campinas, 12(79):213-35, jul.-set. 1952.

ZHANG, W.S. Effects of green manure on organic matter in coastal salinized fluvo-aquic soils. Soils Turang, Beijing, 19(1):36-40, 1987. Apud Soils and Fertilizers, Wallingford, 52(10):1354, 1989. (Resumo). 


\section{BIBLIOGRAFIA RECOMENDADA}

MIYASAKA, S.; CAMARGO, O.A.; CAVALERI, P.A.; GODOY, I.J.; WERNER, J.C.; CURI, S.M.; LOMBARDI NETO, F.; MEDINA, J.C.; CERVELLINI, G.S.; BULISANI, E.A. Adubação orgânica, adubação verde e rotação de culturas no Estado de São Paulo. 2.ed. Campinas, Fundação Cargill, 1984. 138p.

PIETERS, A. J. Green manuring; principles and practice. New York, John Wiley, 1927. 356p.

SYMPOSIUM ON SUSTEINABLE AGRICULTURE, Manila, 1987. Green manure in rice farming. Manila, IRRI, 1978.

WUTKE, E.B.; BULISANI, E.A.; MASCARENHAS, H.A.A. (Coord.). Curso sobre Adubação Verde no Instituto Agronônico, 1. Campinas, Instituto Agronômico, 1993. 121p. 